\title{
Tenocyte-imprinted substrate: a topography-based inducer for tenogenic differentiation in adipose tissue-derived mesenchymal stem cells
}

Haramshahi, Seyed Mohammad Amin; Bonakdar, Shahin; Moghtadaei, Mehdi; Kamguyan, Khorshid; Thormann, Esben; Tanbakooei, Sara; Simorgh, Sara; Milan, Peiman Brouki; Amini, Naser; Latifi, Noor Ahmad

Total number of authors:

14

Published in:

Biomedical Materials (Bristol)

Link to article, DOI:

$10.1088 / 1748-605 x / a b 6709$

Publication date:

2020

Document Version

Peer reviewed version

Link back to DTU Orbit

Citation (APA):

Haramshahi, S. M. A., Bonakdar, S., Moghtadaei, M., Kamguyan, K., Thormann, E., Tanbakooei, S., Simorgh, S., Milan, P. B., Amini, N., Latifi, N. A., Joghataei, M. T., Samadikuchaksaraei, A., Katebi, M., \& Soleimani, M. (2020). Tenocyte-imprinted substrate: a topography-based inducer for tenogenic differentiation in adipose tissue-derived mesenchymal stem cells. Biomedical Materials (Bristol), 15, [035014]. https://doi.org/10.1088/1748-605x/ab6709

\section{General rights}

Copyright and moral rights for the publications made accessible in the public portal are retained by the authors and/or other copyright owners and it is a condition of accessing publications that users recognise and abide by the legal requirements associated with these rights.

- Users may download and print one copy of any publication from the public portal for the purpose of private study or research.

- You may not further distribute the material or use it for any profit-making activity or commercial gain

- You may freely distribute the URL identifying the publication in the public portal 
ACCEPTED MANUSCRIPT

\title{
Tenocyte-imprinted substrate: a topography-based inducer for tenogenic differentiation in adipose tissue-derived mesenchymal stem cells
}

To cite this article before publication: Seyed Mohammad Amin Haramshahi et al 2020 Biomed. Mater. in press https://doi.org/10.1088/1748$\underline{605 X / a b 6709}$

\author{
Manuscript version: Accepted Manuscript \\ Accepted Manuscript is "the version of the article accepted for publication including all changes made as a result of the peer review process, \\ and which may also include the addition to the article by IOP Publishing of a header, an article ID, a cover sheet and/or an 'Accepted \\ Manuscript' watermark, but excluding any other editing, typesetting or other changes made by IOP Publishing and/or its licensors" \\ This Accepted Manuscript is @ 2019 IOP Publishing Ltd.
}

During the embargo period (the 12 month period from the publication of the Version of Record of this article), the Accepted Manuscript is fully protected by copyright and cannot be reused or reposted elsewhere.

As the Version of Record of this article is going to be / has been published on a subscription basis, this Accepted Manuscript is available for reuse under a CC BY-NC-ND 3.0 licence after the 12 month embargo period.

After the embargo period, everyone is permitted to use copy and redistribute this article for non-commercial purposes only, provided that they adhere to all the terms of the licence https://creativecommons.org/licences/by-nc-nd/3.0

Although reasonable endeavours have been taken to obtain all necessary permissions from third parties to include their copyrighted content within this article, their full citation and copyright line may not be present in this Accepted Manuscript version. Before using any content from this article, please refer to the Version of Record on IOPscience once published for full citation and copyright details, as permissions will likely be required. All third party content is fully copyright protected, unless specifically stated otherwise in the figure caption in the Version of Record.

View the article online for updates and enhancements. 


\section{Tenocyte-imprinted substrate; a topography-based inducer for tenogenic differentiation in adipose tissue-derived mesenchymal stem cells}

Seyed Mohammad Amin Haramshahi ${ }^{1,2}$, Shahin Bonakdar ${ }^{3 \star}$, Mehdi Moghtadaei ${ }^{4}$, Khorshid Kamguyan ${ }^{5}$, Esben Thormann ${ }^{5}$, Sara Tanbakooei ${ }^{1}$, Sara Simorgh ${ }^{2}$, Peiman Brouki-Milan ${ }^{2}$, Naser Amini ${ }^{1}$, Noorahmad Latifi $^{6}$, Mohammad Taghi Joghataei ${ }^{7}$, Ali Samadikuchaksaraei ${ }^{2}$, Majid Katebi ${ }^{8}$, Mansoureh Soléimani ${ }^{1,2,7 \star}$

${ }^{1}$ Cellular and Molecular Research Center, Iran University of Medical Sciences, Tehran, Iran

${ }^{2}$ Department of Tissue Engineering \& Regenerative Medicine, Faculty of Advanced Technologies in Medicine, Iran University of Medical Sciences, Tehran, Iran

${ }^{3}$ National Cell Bank, Pasteur Institute of Iran, Tehran, Iran

${ }^{4}$ Department of Orthopedic Surgery, Rasoul-e-Akram Hospital, Iran University of Medical Science, Tehran, Iran

${ }^{5}$ Department of Chemistry, Technical University of Denmark, Kongens Lyngby, Denmark

${ }^{6}$ Department of Plastic and Reconstructive Surgery, Hazrat Fatemeh Hospital, Iran University of Medical Sciences, Tehran, Iran.

${ }^{7}$ Department of Anatomical Sciences, Iran University of Medical Sciences, Tehran, Iran

${ }^{8}$ Department of Anatomy, Hormozgan University of Medical Sciences, Bandar Abbas, Hormozgan, Iran

\section{Corresponding Authors:}

$\star$ National Cell Bank, Pasteur Institute of Iran, P.O. Box 1316943551, Tehran, Iran

E.mail Address: shahinbonakdar@yahoo.com, Shahin Bonakdar

$\star$ Cellular and Molecular Research Center, Iran University of Medical Sciences, Tehran, Iran

E.mail Address: mansourehsoleimani@gmail.com, Mansoureh Soleimani 


\begin{abstract}
Tendon tissue engineering based on stem cell differentiation has attracted a great deal of attention in recent years. Previous studies have examined the effect of cell-imprinted polydimethylsiloxane (PDMS) substrate on induction differentiation in stem cells. In this study, we used tenocyte morphology as a positive mold to create a tenocyte-imprinted substrate on PDMS. The morphology and topography of this tenocyte replica on PDMS was evaluated with scanning electron microscopy and atomic force microscopy. Then the tenogenic differentiation induction capacity of tenocytes replica in ADSCs was investigated and compared with other groups including tissue replica (Which was produced similar to the tenocyte replica and was evaluated by SEM), decellularized tendon, and BMP-12 as other potentially inducers. This comparison gives us an estimate of the ability of tenocyte-imprinted PDMS (which called cell replica in the present study) to induce differentiation compared to other inducers. For this reason ADSCs were divided into 5 groups including control, cell replica, tissue replica, decellularized tendon and BMP-12. ADSCs were seeded on each group seperately and investigated by real-time RT-PCR after 7 and 14 days. Our results showed that in spite of the higher effect of growth factor on tenogenic differentiation, cell replica can also induce tenocyte marker expression (Scleraxis and Tenomodulin) in ADSCs. Moreover, tenogenic differentiation induction capacity of cell replica was greater than tissue replica. Immunocytochemistry analysis revealed that ADSCs seeding on cell replica for 14 days led to Scleraxis and Tenomodulin expression at the protein level. Also, immunohistochemistry indicated that contrary to the promising results in vitro, there was little difference between ADSCs cultured on tenocyte-imprinted PDMS and untreated ADSCs. The results of such studies could lead to the production of inexpensive cell culture plates or biomaterials that can induce differentiation in stem cells without growth factors or other supplements.
\end{abstract}

Keywords:

Cell and tissue Imprinting, Tenogenic differentiation, ADSCs 


\section{Introduction}

The emerging aspect of musculoskeletal tissue engineering has been attempting to address serious tendon problems-which usually occur during exercise and other intense physical activities- through a variety of new techniques (1-3). Due to low cellularity and vascularity and limited innervation, the regeneration of tendon injuries is usually not performed spontaneously (4-7). Clinical interventions including autograft and allograft transplantation as well as suturing, are associated with some problems and obstacles such as donor site morbidity, infection risk, and injury relapse $(8,9)$. Hope for the production of engineered or three-dimensional personalized tendon tissues that are designed to promote the healing of damaged tissues rise due to a recent innovation in the field of regenerative medicine and material science $(10,11)$. To treat defects, various tendon substitutes were developed using synthetic and natural polymers such as poly-lactic glycolic acid (PLGA), Polycaprolactone $(\mathrm{PCL})(12,13)$, chitosan and collagen subclasses and deploying advanced technologies (14-17).

To develop functional tendon, cell-based tissue engineering can be the most promising solution. Since the tendon matrix is made by fully differentiated cells called tenocytes, these cells are the first choice to repair the tendon injuries(18). However, the isolation of tenocytes requires an invasive surgery to harvest the tendon tissue and results in donor site morbidity(19). Also the proliferation of tenocytes in the culture medium can be time-consuming and result in dedifferentiation of these cells $(3,18,20)$. As a result, in recent years many studies have been focused on tendon tissue engineering using stem cells $(21,22)$. Adipose tissue-derived mesenchymal stem cells are considered as an available candidate for the stem cell-based strategies for tendon regeneration due to their large number in the adult body, high proliferation, and differentiation ability, and ease of isolation with little donor site morbidity $(3,23)$.

It is well understood that biochemical factors can change the behavior and fate of stem cells(24). Recent researches are promising in presenting that the tenogenesis could be improved through differentiation induction using/BMP-12, BMP-13, BMP-14, TGF-beta III, and CTGF signaling molecules(25-28). Despite promising results, the use of growth factors has some limitations. Studies have shown that different growth factors are active in different phases of tendon healing process. Different growth factors play different roles in tendon healing(29). Therefore growth factors must be customized for each condition. In other hands, growth factors can trigger unwanted 
molecular pathways and lead to stem cell differentiation to other lineage(18, 30). Further studies are needed to improve the efficacy of growth factor-based approaches and to better understand the molecular pathways involved, as well as the effect of growth factors on the stem cell commitment $\operatorname{process}(31)$.

In addition, microenvironment-mediated biophysical signals can also affect stem cell proliferation, migration, and differentiation (32-34). Currently, biomaterials are designed to transmit specific messages to the cells and control their behavior(2). Many studies have been performed to investigate the effect of biophysical factors on induction differentiation in stem cells. Islam and colleagues have shown the importance of surface stiffness on induction tenogenic differentiation in bone marrow mesenchymal stem cells (35). Other studies demonstrated that changing geometry, cell shape, and matrix elasticity in 2D substrates and 3D microenvironment can change cell fate and lineage commitment (36-40). So far, many studies have been conducted to examine topographical cues as a biophysical factor on stem cell differentiation into many types of cells including tenocytes (41-45). It is demonstrated that nanotopography with alteration in cellular morphology and F-actin alignment can differentiate neural stem cells toward astrocytes and neurons (46). It has also been reported that the topography can alter the human embryonic stem cell response to bFGF (47). Topographical cues also have been used to induce myogenic differentiation in human bone marrow mesenchymal stem cells and it was found that biomimetic nanotopography in combination with electro-conductivity can increase myogenic marker expression(48). Due to the specific structure of the tendon tissue and the arrangement of collagen fibers, the role of the substrate and especially the topography in inducing the tenogenic differentiation in the cells have received much attention. Many studies have focused on the induction of tenogenic differentiation in stem cells using topography $(49,50)$. In a study, it was demonstrated that aligned fibers with or without BMP-12 can increase tendon makers in vitro (51). In addition, Zhang et al. utilized ultrafine fibers to induce tenogenic differentiation in human induced pluripotent stem cells based on mimicking tendon microstructure and topographical features (2).

Various methods including replica modeling, Nanoimprint lithography, Photolithography, Microcontact printing, etc. have been used to create surface topography so far(52). In some studies, cell or tissue morphology has been used as a template for producing negative molding substrates on polydimethylsiloxane (PDMS) $(30,53)$. The basis of this method is to imprinting the 
morphology of cells and tissues at the micrometer and nanometer scales in PDMS. Mahmoudi et al., induced chondrogenic differentiation in rabbit adipose tissue-derived mesenchymal stem cell using chondrocyte-imprinted substrate (53). Mashinchian and colleagues indicated that stem cell culturing on a substrate patterned by keratinocyte cell shape influences the nucleus shape of stem cells and gene expression (54). In other studies, cell imprinting method was used to induce differentiation in mesenchymal stem cells and modulate trans-differentiation $(30,55)$. Despite the testing of various methods based on biochemical and biophysical cues, the best way to induce tenogenic differentiation is still unclear. On the other hand, the efficacy of inducing differentiation using biophysical factors such as topography is still controversial $(3,56)$. In this study, it has been attempted to investigate whether imprinting tenocyte morphology on PDMS can produce a sheet capable of enhancing the expression of tenocyte markers in mesenchymal stem cells. Various studies have used BMP-12 as an inducer of tenogenic differentiation. Therefore, the potential of induction tenogenic differentiation of tenocyte-imprinted PDMS substrate was compared with the BMP-12 (as a positive control group) and other potential inducers including tendon tissue imprinted PDMS and decellularized tendon. In the next part of this study, the expression of specific tenocyte protein markers in mesenchymal stem cells cultured on tenocyte-imprinted PDMS was investigated, and finally, the behavior of cells cultured on this sheet was studied in vivo. Studying this method can help to provide inexpensive, reliable and effective PDMS sheets that can be used for induction tenogenic differentiation in mesenchymal stem cells.

\section{Material and methods}

\subsection{Ethical approval}

This study was confirmed by the ethical committee of Iran University of Medical Sciences (IUMS ethical code: IR.IUMS.REC1395.9221565204) to use human-derived tissues and animal experiments and conducted based on the national guidelines. 


\subsection{Study design}

This study is divided into in vitro and in vivo sections. A) In vitro investigations: in order to evaluate and compare the tenogenic marker expression in mesenchymal stem cells cultured on human tenocyte imprinted PDMS with other groups including tendon tissue imprinted PDMS, decellularized tendon and BMP-12 on induction tenogenic marker expression in human ADSCs, we designed 5 study groups which were individually affected by different conditions. These five groups are 1) ADSCs with no treatment as a control group. 2) ADSCs that were treated with 100 ng/ml BMP-12 (GF; Growth factor group). 3) ADSCs which was seeded on human tenocyte replica on PDMS without additional treatment (CR; cell replica group). 4) ADSCs which were seeded on human tendon tissue replica on PDMS without additional treatment (TR; tendon replica group) and 5) ADSCs cultured on the human decellularized tendon (DT group). The capacity of experimental groups to induction tenogenic differentiation was evaluated and compared using realtime RT-PCR analysis. The potency of replicas to the induction of tenogenic markers expression at the protein level was evaluated using immunocytochemistry:

B) In vivo investigations. Rat cells were used for in vivo investigations. After tenocyte isolation and characterization from rat, rat tenocyte replica was fabricated. Then rat adipose tissuederived mesenchymal stem cells were seeded on rat tenocyte replica for 14 days and then were transplanted into rat subcutaneously using an electrospun PCL mat. Also, differentiation of rat stem cells to tenocytes after 14 days of culture on cell replica was confirmed by immunocytochemistry (results not shown).

\subsection{Isolation, culture, and characterization of ADSCs}

Human adipose tissue-derived stem cells have been isolated based on published protocols (57). Briefly, the adipose tissue samples were obtained from 5 healthy 30-35 years old men, during abdominal liposuction and transferred to the laboratory in a sterile dish containing Phosphate Buffer Saline (PBS) and antibiotic. Next, the samples were chopped into the $1 \mathrm{~mm}^{3}$ pieces, incubated with Dulbecco's Modified Eagle's Medium (DMEM, Gibco, UK) containing $1 \mathrm{mg} / \mathrm{ml}$ collagenase type $\mathrm{I}$ at $37^{\circ} \mathrm{C}$. The mixture was gently shacked every 15 minutes during digestion. After 1 hour, the prepared suspension centrifuged at $1200 \mathrm{rpm}$ for $5 \mathrm{~min}$ at $25^{\circ} \mathrm{C}$. Then supernatant was removed and cell pellets were cultured in DMEM/Ham's F-12 (Gibco, UK) supplemented 
with $10 \%$ Fetal Bovine Serum (FBS, Gibco, UK) and $1 \%$ penicillin (100 IU/ml, Sigma Aldrich, US $/$ streptomycin $\left(100 \mu \mathrm{g} / \mathrm{mL}\right.$, Sigma Aldrich, US) and incubated $\left(5 \% \mathrm{CO}_{2}, 95 \%\right.$ humidity). After $48 \mathrm{~h}$, the supernatant containing debris, dead cells, and erythrocytes was replaced by a fresh medium. The isolated cells were characterized using flow cytometry and multi-lineage differentiation assay after passage 3. ADSCs from 5 adult rats (250-300 g, 6-8 weeks old, male) were similarly isolated.

The isolated mesenchymal stem cells from adipose tissue with fibroblast-like morphology expressed mesenchymal lineage-specific markers including CD73, CD90, and CD105 (98.75\%, $99.4 \%$, and $99.3 \%$, respectively) and did not express CD34 and CD45 according to flow cytometry results. In addition, Tri-lineage differentiation assay was performed and ADSCs successfully differentiated into osteocyte, chondrocyte, and adipocyte (see supplementary data 1).

\subsection{Isolation and culture of tenocytes}

Human tendons were harvested from surgical waste obtained from allograft rotator cuff surgery in 5 healthy men (25-30 years old) under ethical consent. Samples were transferred to the lab using a sterile dish containing 3\% Penicillin (100 IU/ml)/Streptomycin $(100 \mu \mathrm{g} / \mathrm{ml})$ dissolved in PBS. For tenocyte isolation, surrounding tissues were removed by a forceps and the tendon was cut into pieces under $1 \mathrm{~mm}^{3}$. After washing with sterile PBS, slices were digested with DMEM containing $5 \mathrm{mg} / \mathrm{ml}$ collagenase type I at $37^{\circ} \mathrm{C}$ overnight. Afterward, the suspension was centrifuged at 1200 RPM for 5 minutes at $25^{\circ} \mathrm{C}$. The cell pellet was cultured after resuspension with DMEM/Ham's F12, supplemented with $10 \%$ FBS and 1\% Penicillin/Streptomycin, and kept in a humidified incubator $\left(37^{\circ} \mathrm{C}\right.$ and $\left.5 \% \mathrm{CO} 2\right)$. The medium was refreshed every 3 days. After collection, Cells were characterized individually and then, the cells were pooled and used for subsequent studies. Rat tenocytes (r-tenocytes) also isolated from Achilles tendon of 5 adult male Wistar rats.

\subsection{Tenocyte characterization using immunocytochemistery}

For characterization of isolated tenocytes, immunocytochemistery was perfrormed. The tenocytes were rinsed twice with PBS followed by fixation using paraformaldehyde 4\% in PBS ( $\mathrm{pH}=7.2)$ for 20 minutes at $25^{\circ} \mathrm{C}$. After removing the fixative solution, the cells were washed with PBS for 3 
times and permeabilized with $0.2 \%$ (v/v) Triton X-100 in PBS for 40 minutes. Following that, cells were washed using PBS ( 3 times) and incubated with BSA $1 \%$ in PBS at $37^{\circ} \mathrm{C}$ for $1 \mathrm{~h}$ to block non-specific antigen-antibody reactions. Next, they were incubated with primary antibodies against scleraxis (1:250, ab58655, Abcam, UK) and Tenomodulin (1:200, orb101154, Biorbyt, UK) at $4^{\circ} \mathrm{C}$ overnight. Finally, anti SCX treated samples were incubated with Alexa Fluor ${ }^{\circledR}$ 647conjugated secondary antibody (1:300, ab150079, Abcam, UK) and Anti tenomodulin treated samples were incubated with Alexa Fluor ${ }^{\circledR}$ 488-conjugated secondary antibody (1:300, ab150077, Abcam, UK) for $1 \mathrm{~h}$ in the darkness at $25^{\circ} \mathrm{C}$. DAPI staining ( $1 \mu \mathrm{g} / \mathrm{ML}$, Sigma) was used for nuclei detection. After immunocytochemistry, the samples were imaged using fluorescent microscopy (Olympus, Japan). Then by dividing the cells expressing TNMD (as a specific marker of adult tenocytes) by the total number of cells, it was shown that in different samples, on average, $93 \%$ of cells expressed TNMD.

\subsection{Fabrication of Cell and Tissue replica}

Cell and tissue replicas were fabricated based on previously published protocols (53). Briefly Human and rat tenocytes (h-tenocytes and r-tenocytes) at passage 1 were cultured (Separately) at a density of $3 \times 10^{3} / \mathrm{cm}^{2}$ in 6 well plates. After 48 hours, the medium was removed and cells were rinsed using PBS and fixed by glutaraldehyde $2.5 \%(\mathrm{~V} / \mathrm{V})$ at $4{ }^{\circ} \mathrm{C}$ overnight. Polydimethylsiloxane (PDMS, SYLGARD 184, RTV, Dow Corning, USA) was mixed with the curing agent (1:10) and the mixture was cast onto the cells and they were kept at $37^{\circ} \mathrm{C}$. After 48 hours, the PDMS that was perfectly molded was gently removed from the cells $(53,54)$.

For human tendon tissue imprinting, human rotator cuff tendon was sliced into $60 \mu \mathrm{m}$ diameter slices with longitudinal cuts using cryostat. Then, the slices were placed at the bottom of the 6 well cell culture plate and after drying, the tendon replica was prepared via casting PDMS on the slices. Prior to using the PDMS samples, chemical and biological materials that could have remained on them were eliminated using $1 \mathrm{M} \mathrm{NaOH}$ solution at $90^{\circ} \mathrm{C}$.

\subsection{Cell seeding on Cell Replica and Tendon replica}

Human ADSCs $\left(10 \times 10^{3}\right.$ cells $/ \mathrm{cm}^{2}$ in $50 \mu \mathrm{L}$ of culture medium $)$ were seeded on the cell and tissue replica and then the samples were incubated at $37^{\circ} \mathrm{C}$. After $3 \mathrm{~h}$ of incubation, 
DMEM/Ham's F12 medium supplemented with FBS 10\% (v/v) was added to each sample, covering the sheet surface completely. The medium was refreshed every 3 days. Cells were collected after 7 and 14 days for gene expression analysis. Also after 14 days of seeding ADSCs on cell replica and tissue replica, cells were fixed for immunocytochemistry. For evaluation cell alignment on PDMS after immunocytochemistry the average aspect ratio of cell nuclei (major axis/minor axis) was measured using ImageJ software. 100 cell nuclei were used in each groups.

\subsection{Tendon decellularization and recellularization}

Human rotator cuff tendon was cut into $1 \mathrm{~cm}^{3}$ segments and then kept in sterile deionized water for $2 \mathrm{~h}$. Afterward, tissue segments were washed using $1 \%$ EDTA in deionized water at $25^{\circ} \mathrm{C}$ for 4 hours. Samples were rinsed 3 times using PBS containing 3\% Penicillin/Streptomycin and then were treated with $0.1 \%$ SDS solution in PBS for $24 \mathrm{~h}$. After 3 times washing with PBS, tendon segments were incubated for $24 \mathrm{~h}$ with a hypertonic solution containing potassium chloride $(\mathrm{KCl})$ 5 Molar and 1\%(w/v) Triton X-100. Samples were preserved at $-80 \mathrm{C}$ before use. The tendon decellularization was evaluated by Hematoxylin and Eosin (H\&E) staining and DNA content assay. Also, the decellularized tendon was imaged by SEM to investigate the structure and integrity of the tendon tissue after decellularization. To recellularize, h-ADSCs were seeded at a density of $1 \times 10^{6} / \mathrm{cm}^{2}$ in $20 \mu \mathrm{L}$ culture medium and left for 2 hours. Ultimately culture medium was added to all samples to cover tissues.

\subsection{Scanning Electron Microscopy (SEM) and Atomic force microscopy (AFM)}

SEM microscopy was performed to investigate the microstructure of tendon tissue, pattern, and topography of cell replica and tissue replica and cell morphology on sheets. For cell fixation, $2.5 \%$ glutaraldehyde was added to all samples so as to cover all the sheets. All samples were dehydrated using ethanol with increasing concentration (serial dilution 50-100\%). After drying, the specimens were coated with a thin layer of gold and then were viewed under a TESCAN VEGA3 SEM at an accelerating voltage of $30 \mathrm{kV}$. In order to investigate the topography of cell replica, AFM (NanoWizard 4a NanoScience, JPK Instruments AG, Berlin, Germany) contact 
mode imaging was performed. A rectangular cantilever (HQ:NSC18/Al BS, MikroMasch, Bulgaria) was used with spring constant of $2.8 \mathrm{~N} / \mathrm{m}$ and a conic tip of $8 \mathrm{~nm}$ radius. Using a scan rate of $0.05 \mathrm{~Hz}$ and setpoint force of $0.5 \mathrm{nN}$, surface areas up to $100^{2} \mu \mathrm{m}$ were scanned. Image analysis was done using standard software of the instrument (JPKSPM Data Processing).

\subsection{Real-time polymerase chain reaction (PCR)}

To extract RNA, all samples were directly lysed using Trizol according to manufacturer protocol. Genomic DNA was eliminated using DNase I. RNA concentration and purification were evaluated by $260 / 280$ absorbance ratio using nanodrop (Thermo scientific, USA). A mix solution containing $1 \mu \mathrm{g}$ of RNA, $0.5 \mu \mathrm{l}$ of oligo dTs, and $0.5 \mu \mathrm{l}$ of random hexamer were combined. Finally, the cDNA construct was synthesized using the cDNA Synthesis Kit (PrimeScript RT Master Mix, TAKARA, Kyoto, Japan) according to the manufacturer's protocol.

For quantitative PCR, $1 \mu 1$ of synthesized cDNA, $13 \mu 1$ Maxima SYBR Green/ROX qPCR Master Mix kit (Thermofisher, USA), $0.5 \mu$ l of each primer, and $10 \mu 1$ deionized water were mixed at $25 \mu \mathrm{l}$ total volume and PCR was performed using Rotor-Gene 6000 instrument (Corbett Life Science, Australia). Scleraxis (SCX), Tenomodulin (TNMD), and Tenascin C (TNC) were used as tenogenic differentiation markers and GAPDH was used as a housekeeping gene. ADSCs without any treatment has been considered as a control group for normalizing target gene expression. Primer pairs are demonstrated in tablel. Relative expressions were determined using the $\Delta \Delta \mathrm{Ct}$ method relative to gene expression values for control samples. Each PCR reaction was carried out in triplicate.

[Table 1]

\subsection{In vivo investigations}

To study in vivo behavior of topography-induced tenogenic differentiation of ADSCs, the cultured rat ADSCs (r-ADSCs) on a cell replica of rat tenocytes, after 14 days of incubation, were 
detached by trypsinization, and then were labeled with DiI stain (Sigma), seeded on a Poly ( $\varepsilon$ caprolactone)-based electrospun mat and kept for $24 \mathrm{~h}$. Wistar rats (6 male, 250-300 g) were anesthetized via injecting the mixture of ketamine and Xylazine $(70 \mathrm{mg} / \mathrm{kg}$ and $10 \mathrm{mg} / \mathrm{kg}$, respectively). A pocket was made through an incision in the median backside and electrospun mat/ containing cells was transplanted into the pocket. Cyclosporine A as an immunosuppressive drug $(10 \mathrm{mg} / \mathrm{Kg})$ was injected intravenously every day. At the end of week 4 rats (in each group) were sacrificed using $\mathrm{CO}_{2}$ inhalation and the tissue samples were harvested for histological evaluations. Also, PCL electrospun mats without cells were used as control negative group and ADSCs group including electrospun mats carrying untreated ADSCs were transplanted into rats. Collagen type I expression were imaged in each group by fluorescence microscopy with 100x magnifications (olympus ix71, Japan). In each group, different fields were randomly imaged and 5 images were analyzed in each group. The amount of Collagen I expression (green) was analyzed by ImageJ software and revealed as color intensity percent. GraphPad Prism software was used to analyze the results.

2.10. Histological evaluations using Hematoxylin and Eosin (H\&E) staining and immunohistochemistry

For H\&E staining, samples were fixed in $10 \%$ formalin and embedded in paraffin after dehydration and clearing. Then paraffin blocks were sectioned in $5 \mu \mathrm{m}$ slices and stained with hematoxylin and eosin. To investigate the difference of the collagen type I (as the main component of tendon ECM) production capacity in tenogenic differentiation induced ADSCs with the control group, the Immunohistochemistry technique was performed.. Briefly, after deparaffinization and hydration of tissue samples, antigen retrieval was performed via incubation in sodium citrate $(0.01 \mathrm{M})$ at $120^{\circ} \mathrm{C}$ for 11 minutes using an autoclave (Memert, Germany). Tissue sections were treated with a blocking solution consisting of 1\% bovine serum albumin (BSA; Sigma Aldrich) and 1\% Triton 
X-100 (Sigma Aldrich) in PBS for 60 minutes at $25^{\circ} \mathrm{C}$. The specific primary antibody against collagen type I (1:200, ab34710, Abcam, UK) was added to each sample and incubated at $4{ }^{\circ} \mathrm{C}$ overnight. Next, the Alexa Fluor ${ }^{\circledR} 488$-conjugated secondary antibody (1:300, ab150077, Abcam, UK) was added to each sample and samples were kept at $25^{\circ} \mathrm{C}$ and in darkness for 45 minutes. For nuclei staining, samples were exposed to DAPI $\left(1 \mu \mathrm{g} / \mathrm{mL}\right.$, Sigma Aldrich) for 10 minutes at $25^{\circ} \mathrm{C}$.

\subsection{Statistical analysis}

All data were expressed as means \pm SD of three separate experiments. Statistical significance was evaluated by two-way ANOVA and Fisher's LSD (GraphPad Prism ver. 7.04). A $P$ value less than 0.05 was regarded as statistically significant.

\section{Results and discussion}

\subsection{Microscopic observations}

The isolated tenocytes from human rotator cuff illustrate bipolar and spindle-shaped morphology like fibroblasts (Fig. 1, a1-a4). Immunocytochemistry assay demonstrated that most of cells expressed Scleraxis and Tenomodulin proteins as specialized tendon markers (Fig. 1, b1-b6).

As can be seen in figure 2 (a-d and g), cell morphology is well imprinted on PDMS substrate and the appearance of the cell replica on PDMS was similar to the cell morphology in 2D culture. According to the SEM images, the morphology of h-tenocytes and tendon tissue sections were successfully imprinted on PDMS (Fig. 2e-2g). Data showed that alignment and microstructure of the tendon tissue were similar to its replica (Fig. 2e and 2f). Furthermore, AFM analysis revealed that the h/r-ADSCs and the h/r-tenocyte-imprinted PDMS (as called cell replica; CR) showed differences in height and morphology (see Fig. 3e). According to these results, the footprint of cells in each group (stem cells and tenocytes) seems to be different from others and specific (Fig. 3e). The differences in surface topography between h-tenocyte and h-ADSCs can be considered as a result of the existing differences in cell cytoskeleton and cell membrane. As mentioned in the literature, cytoskeleton composition and structure plays an essential role in cellular morphology $(58,59)$. Furthermore, the similarity of surface topography between $\mathrm{h} / \mathrm{r}$-tenocytes 
seems be higher than the similarity between the tenocytes and ADSCs in the same species based on AFM analysis (see Fig. 3e). Recently, researchers found that the cell surface pattern can be imprinted in nano and micro-scale using PDMS(53). On the other hand, it has been shown that the cytoskeleton structure influences nucleoskeleton organization resulting in chromosome remodeling which may have regulatory effects on gene expression profile $(54,60,61)$. There is increasing evidence that the nuclear structure can control heterochromatinization(62). Also, studies have been shown the nucleus structure can affect gene expression via controlling transportation and sequestration of transcription factors(62). In this study, the molecular pathways of differentiation induction have not been investigated. However, by reviewing similar studies, we can find that integrin can be one of the important candidates for mediating differentiation induction via biophysical signals. The integrins transmit biophysical signals to the nucleus through focal adhesions and actin, which contributes to the structure of the cytoskeleton. The transmission of these signals, resulting from the molecular interactions between focal adhesion, the cytoskeleton and the structure of the cell and nucleus, ultimately leads to the regulation of gene expression(63). So far, cell shape and especially nucleus structure have been neglected in designing biomaterials.

[Figure 1]

\section{[Figure 2]}

[Figure 3]

\subsection{Decellularized tendon investigation}

Natural extracellular matrix of the tendon was prepared by decellularization method using chemical materials. H\&E staining confirmed that all cells were removed from the fresh tendon tissue while its structure was preserved. Additionally, the collagenous structure of the decellularized tendon was similar to the native one (Fig. 4). The results of the DNA content assay also showed that the cells were well removed from the tissue. As shown in the Fig 4c, the DNA content decreased significantly after tendon decellularization as compared to native tissue $(p<0.0001)$. The DNA content assay results were in good agreement with the H\&E images of the decellularized tendon. Also, SEM image showed that the tendon tissue integrity was maintained after decellularization. 
In the studies undertaken, both SDS and Triton X-100 caused human tendon decellularization successfully (64). It also demonstrated that tendon collagen and its mechanical properties were successfully preserved after decellularization using chemical detergents $(64,65)$.

[Figure 4]

\subsection{Cell attachment on Cell Replica and Tendon Replica}

As shown in Figure 5, the cells were well attached to the surface of PDMS. Also ADSCs were expanded on PDMS during 7 and 14 days of incubation. After stem cell seeding on cell replica, the cells began to aggregate and created colony-like structures. At the end of the first week following the cell seeding, in both CR and TR group, the cells began to organize and by the end of the second week, the seeded cells in CR group, developed well-organized and well-aligned structures (Fig. 5, $\mathrm{a}, \mathrm{b}$, e and h). As shown in figure 5a, 5c, 5d, after seven days of seeding h-ADSCs on cell and tissue replica, they started to aggregate and formed round structures. These aggregations are interconnected through cellular processes and then, cell aggregations joined together and formed aligned structures in the CR group (Fig. 5, a-c, e and h). Consistent with the previous studies results, cell replica successfully effects on cell fates $(30,53,54)$. More specifically, after culturing, cell alignment could be seen as a sign of altering cell behavior Fig.5 (e and h) clearly shows the aligned structures constructed by the cells seeded on cell replica. As can be seen in the Fig. 5 (b, e and $\mathrm{h}$ ), these structures are present in the center of the substrate. These structures are found in all CR substrates 14 days after seeding ADSCs. The results also showed that aspect ratio in CR group was significantly higher than the TR and the control group (see supplementary data 2$)(p<0.0001)$. The results of the aspect ratio measurement are quite consistent with what is observe in the Fig. 5 (b, e and h).This cellular behavior, which is associated with the expression of tenocytic markers on the 14th day, can be a sign of cell differentiation and their tendency to form tissue-like structures. Additionally, the effect of substrate on alignment and orientation of cells has been studied $(66,67)$. The effect of cell alignment on tenogenic differentiation has been evaluated in some studies. Wu and his colleagues showed that aligned fibers can promote cell proliferation and cell alignment as well as tenogenic marker expression(68). It has also been shown that the differentiation of stem cells into tenocytes are associated with increased cell alignment(69). The 
results of the present study also confirm that the increased expression of tenocyte markers is directly related to cell alignment.

\section{[Figure 5]}

\subsection{Real-time PCR analysis}

Tenogenic markers expression including SCX, TNMD, and TNC were found following 7 days of culturing. In fact, a high level of SCX and TNMD as early and late tenocyte markers were detected only in the GF group compared to other groups (3.1 Fold and 4.3 Fold respectively, $\mathrm{p}<0.01$ for SCX and $\mathrm{p}<0.05$ for TNMD), while, the level of TNC expression (as a marker of tendon extracellular matrix) only in TR (tendon replica) group was higher significantly than the control group $(\mathrm{p}<0.05)$. Moreover, at this time, the level of SCX expression/in the GF group was significantly higher than the CR group $(\mathrm{p}<0.05)$ while there was no significant difference between GF and other groups. In addition, no significant difference was detected in TNMD expression between the GF and other groups after 7 days of culturing. These findings mean that it was not enough time for physical cues or even the natural tissue (decellularized tendon) to induce tenogenic differentiation in the cultured h-ADSCs. Also, this study was undertaken to examine the expression of tenogenic markers at days 14. The GF and CR groups showed significant high expression of $\mathrm{SCX}$ in comparison with the control group ( $\mathrm{p}<0.001$ for GF and $\mathrm{p}<0.05$ for $\mathrm{CR}$ ). In addition the expression of TNMD in GF and CR was significantly higher than the control group ( $p<0.0001$ for GF and $\mathrm{p}<0.01$ for CR). The SCX was increased 2.6 fold and also the TNMD increased 2.5 fold in the CR group when compared to the control. Also, TNMD expression in the GF group was significantly higher than the CR $(p<0.05)$, TR $(p<0.001)$, and DT $(p<0.01)$. Meanwhile, there was no significant increase in TNC expression in comparison with the control group at this time. Also, the expression level of SCX and TNMD in the TR group increased about 1.7 and 2 fold compared to the control group, however this increase was not significant. The results showed that the TR can induce a non-significant increasing expression of tenocytic markers as well. However, the effect of this substrate on the expression of the Tenascin $\mathrm{C}$ marker, which is a marker of the extracellular matrix, is more than its effect on the expression of SCX and TNMD as tenocyte markers.

Consequently, data showed that CR in comparison with TR is significantly more effective in increasing the expression of SCX and TNMD markers than the expression of TNC. In contrast, the TR group increased TNC gene expression. However, this increase does not reach to a 
significant level. In addition, the level of TNC expression of DT group was significantly high compared to the control group after 14 days $(\mathrm{p}<0.05)$.

Results also revealed that the level of SCX expression increased in the DT group up to 2 folds after 7 days and 1.8 after 14 days. Moreover, TNMD expression increased in the DT group rather than the control group after 7 and 14 days, although the increase was not significant. Contrary to these results, in some studies, significant increases in the tenocyte markers in stem cells that have been treated with biophysical and/or biochemical cues have been observed after 7 days (70) While, other studies have shown that the most expression of tenogenic markers are observed after 14 days $(18,30)$. Shen et al showed that the treatment of mesenchymal stem cells with BMP-12 could induce the highest expression of SCX at day 14 post-treatment (18). Also, Bonakdar and colleagues observed that culturing mesenchymal stem cells on patterned sheets for 14 days can increase TNMD expression significantly(30). The results of these studies are in agreement with the results of the present study.

According to results, BMP-12 and decellularized tendon increased the expression of tendon markers in ADSCs. These results are not surprising due to some other studies. Previously, many articles have indicated the effect of BMP-12 in the induction of tenogenic differentiation in stem cells. Zarychta-Wiśniewska et al. found that BMP-12 can activate tenogenic differentiation in human ASCs and can be a suitable candidate for acute tendon injuries but not for chronic injuries(71). In other studies, it has been suggested that BMP-12 can induce tenogenic differentiation in 2D and 3D conditions in vitro alone and in combination with other growth factors such as TGF- $\beta$ and bFGF $(51,72,73)$. The effect of this growth factor in tendon healing in vivo is also demonstrated in some studies $(74,75)$. Also, as shown in some other studies, stem cells cultured on the decellularized tendon tissue can induce tenogenic differentiation and increase tendon specific marker expression $(76,77)$. In this study we did not investigate the molecular pathway of tenogenic differentiation. However, various studies have shown that treatment of cells with BMP-12 increases the expression of Smad family molecules, which ultimately results in increasing the expression of the SCX transcription factor(78). Increased levels of SCX in the cell nucleus result in the expression of various genes, including $\operatorname{TNMD}(78,79)$. Biophysical factors (such as surface topography) can also enhance SCX expression through different molecular pathways $(78,80)$. Our observations in this study also confirm the results of these articles. In this 
study, we observed that treatment of cells with BMP-12 growth factor, as well as cell culture on decellularized tendon, could increase expression of tenocytic markers. Our studies also confirm the studies that have used surface topography to induce tenogenic differentiation in mesenchymal stem cells. Using cell culture on aligned multilayered electrospun, Orr and his colleagues were able to induce the expression of tenocyte markers in adipose tissue mesenchymal stem cells. However, the results of this study showed that the highest expression was observed on day 7 after seeding, which is in contrast to our results(81). The aim of this study was to evaluate the expression of tenocyte markers in stem cells cultured on human tenocyte-imprinted PDMS (human tenocyte replica on PDMS). Comparison of tenocyte markers expression by growth factor-treated stem cells with topography induced cells shows that expression level of tenocyte markers in cells cultured on cell replica is lower than the expression of these markers in growth factor-treated cells. A comparison of gene expression results in the CR group and the GF group shows that the biophysical signal induced by the CR group, although weaker than the biochemical signal of the GF group, is an important and significant inducer. In fact, in this study, the GF group acts as a positive control, allowing us to evaluate the true biophysical signal strength of CR.

\section{[Figure 6]}

\subsection{Immunocytochemistry}

Immunocytochemistry was performed to determine tenogenic differentiation in ADSCs, 14 days after seeding on cell replica and tissue replica. According to figure 7, single cells as well as aligned structures that were mentioned above expressed SCX and TNMD. Data showed that tendon marker expression in ADSCs cultured on tenocyte-imprinted PDMS (CR group) was greater than ones cultured on tissue-imprinted PDMS. In single cells, there was no significant difference detected in the cell morphology and nucleus, however, in cells present in aligned structures, the nucleus was more aligned. Also, cell aggregations were lower and smaller in ADSCs cultured on tissue replica as well as tenocyte marker expressions (Fig. 7). Additionally, immunocytochemistry images demonstrated that the topography-induced ADSCs, successfully express tenogenic markers at protein level after 14 days of culturing on the patterned sheet (including CR and TR), indicating the successful differentiation of these cells. However, the cell 
morphology and SCX and TNMD expression in CR and TR group after 14 days were similar to adult tenocytes (that illustrated in Fig. 1). Cultured cells on cell replica formed larger and more regular structures than cells on tissue replica. These results are consistent with the results of the gene expression which indicate that $\mathrm{CR}$ has a stronger effect on induction of differentiation than TR. It has been well known that the Scleraxis is a member of class II basic helix-loop-helix transcription factors that is important for tendon formation and development during embryogenesis and tendon regeneration. It has also been shown that scleraxis plays an important role in tenogenic differentiation in mesenchymal stem cells $(84,85)$. Tenomodulin (TNMD) is a type II glycoprotein transmembrane glycoprotein which is highly expressed in mature tendon and ligaments and it is known as a marker for tenocytes detection $(79,86)$. Furthermore, studies have shown that SCX acts as one of the upstream regulators of $\operatorname{TNMD}(79,87)$.

[Figure 7]

\subsection{Immunohistochemistry and H\&E staining}

IHC staining showed that the DiI-labeled ADSCs that induced by cell replica topography on the electrospun mat can express collagen type I, which is the main component of the tendon ECM, . Despite the results of in vitro tests, cells cultured on cellular replica did not show significant extracellular tissue production in vivo compared to untreated stem cells. Collagen type I formation is expected in all three groups due to the migration of host cells to the electrospun mat. The production of type I collagen in CR group and ADSC group was higher than acellular electrospun mat group, however, there is little difference between ADSCs and cells cultured in CR, which could be the result of higher differentiation of cells of the CR group (Fig 8, a1-c4). The absence of significant differences between CR and ADSCs may be due to subcutaneous inappropriate conditions for tendon-like tissue production.

As can be seen in Figure 8d, H\&E staining also showed that the tendon ECM like structures were formed in the CR group (Fig. 8, d2) and it seems at a high level in comparison with the control negative group (Fig. 8, d1). Although the ADSC group also contains large numbers of cells as well as significant ECM-like structures (Fig. 8, d3), the shape of these structures differ from that of the $\mathrm{CR}$ group and do not form tendon-like structures. The nuclei morphologically were oval-shaped and aligned with the direction of the tissue-like structure while in the control group and in ADSC group the nuclei were round with no specific orientation (Fig. 8, d1-3). 
Despite the many studies about the differentiation of stem cells into tenocytes using physical cues such as topography, the results of these studies are still controversial. English et al., in their study, concluded that although topography is effective in maintaining tenogenic phenotype in vitro, it cannot produce tissue in the in vivo and ectopic conditions(56). In the present study, the results are almost similar to those of English et al., and despite the promising in vitro results, the in vivo results are not very satisfactory. However, there are other studies showing that cells treated with biophysical factors can also repair damaged tendon tissue in vivo. Xu et al. using heterotopic transplantation, evaluated neo-tendon maturation potency of their tendon derived stem cell-seeded constructs (88). In another study, Ni and colleagues were able to produce tendon-like tissue subcutaneously without using scaffolds and only using tendon-derived mesenchymal stem cells(89). The results of the Ni study, in contrast to the results of the present study, show that in vitro treated mesenchymal stem cells are capable of producing tendon-like tissue in vivo.

[Figure 8]

\section{Conclusion}

The focus of this study lies in evaluating the impact of tenocyte-imprinted PDMS (as called cell replica or tenocyte replica in this study) as a topography based approach on induction tenogenic differentiation in mesenchymal stem cells.

What is revealed through this study is that the cell-based topography has a significant effect on tenogenic differentiation, although the effect of topography is lower than the growth factor. On the other hand, the results showed that the topography of tendon fibers also has a significant effect on tenogenic marker expression in tendon replica and decellularized tendon. Our results showed that cell replica is more effective on induction tenogenic marker expression than tissue replica.

Our findings may be used to design biomaterials since they have been more focused on the shape and structure of the extracellular matrix. Although the effect of growth factor on tenogenic differentiation is more than cell and tissue imprinted substrate, the remarkable impact and the advantage of physical cues in inducing tenogenic differentiation can lead us to further study on the effects of topography. 
It seems that the biophysical cues (e.g. topography) are safe and more cost-effective than chemical cues (e.g. growth factors) for clinical applications, using these factors should be given more attention.

On the other hand, despite the advantages of the cell imprinting method, it has some limitations. One of these limitations is the low efficiency of this method compared to biochemical factors such as growth factors. Also, cell culture on these substrates is stochastic, and cell placement in cell replica cannot be controlled. After all, there are still many questions about the effectiveness of biophysical based methods. Overall, it seems that studies need to continue in this regard to address all the ambiguities.

\section{Acknowledgment}

This research was supported by grant No 94-05-87-27505 from Iran university of medical sciences.

\section{Figure captions:}

Supplementary data 1. h-ADSCs characterization. (a) 5 days after isolation. (b) 15 days after isolation. Oil red $\mathrm{O}$, Alizarin red $\mathrm{S}$ and toluidine blue staining was used to confirm adipogenic (c), osteogenic (d) and chondrogenic (e) differentiation capacity of adipose tissue-derived cells (scale bar $=100 \mu \mathrm{m}$ ). Also, flow cytometry results confirmed that iso lated cells are express mesenchymal stem cell markers and do not express hematopoietic markers (f).

Supplementary data 2. The effect of substrate topography on aspect ratio of cell nuclei. Aspect ratio of ADSCs nuclei cultured on cell replica was significantly higher than that cultured on TR and control group ( $\mathrm{p}<0.0001)$.

Supplementary data 3. Immunocytochemistry staining to confirm tenogenic differentiation in hADSCs, 14 days after seeding on cell replica. (a1 and b1) Cell nuclei stained by DAPI (blue), SCX and TNMD protein expression stained by Alexa Fluor ${ }^{\circledR}$ 488-conjugated goat anti-rabbit antibody (green). (a2 and a3) SCX expression in aligned structure of ADSCs cultured on the h-tenocyte replica (scale bar $=200 \mu \mathrm{m}),(\mathrm{b} 2-\mathrm{b} 3)$ TNMD expression in single h-ADSC cultured on the htenocyte replica (scale bar $=100 \mu \mathrm{m})$. 
Fig 1. Human tenocyte characterization 10 days after isolation. (a-d) Morphology and size of isolated cells from human tendon under invert microscope was identical with h-tenocyte (days 5 , 10, 15 and 20)(scale bar $=100 \mu \mathrm{m})$, (b1) Scleraxis expression and (b4) Tenomodulin expression, (b2) and (b5) show nuclei with DAPI staining, (b3) and (b6) show overlay images of DAPI and protein expression $($ scale bar $=100 \mu \mathrm{m})$.

Fig 2. Cell and tissue imprinting on PDMS. Invert microscope images of (a) Fixed h-tenocytes, (b) tenocytes replica on PDMS, (c) Fixed h-ADSCs, (d) h-ADSCs replica on PDMS (a-d, scale bar = $100 \mu \mathrm{m})$, SEM images of (e) human tendon section, (f) tendon tissue replica on PDMS, (g) a single h-tenocyte replica on PDMS.

Fig 3. AFM image analysis of cell replica topography. (a) h-ADSC, (b) r-ADSC, (c) h-tenocyte, (d) r-tenocyte. (e) Image analysis by the JPKSPM Data Processing software shows some differences in the height and shape of the cell surface of the cell replicas on PDMS, reflecting the topographic difference at the cell surface.

Fig 4. Human tendon decellularization. $H \& E$ images of Native human tendon (a) and decellularized tendon (DT) (b). The results of DNA content assay (c) and SEM image of decellularized tendon $(\mathrm{d})$.

Fig 5. Cell attachment on PDMS (CR and TR). The left column shows the h-ADSCs attachment on cell replica 7 days after seeding. The middle column shows the h-ADSCs attachment on cell replica 14 days after seeding. The right column shows the h-ADSCs attachment on tissue replica 7 days after seeding. Cells did not show much change after 14 days of culture on TR, and therefore the image of day 14 was deleted. (a-c) invert microscope image of ADSCs aggregations on h- 
tenocytes and tendon tissue replica (scale bar $=200 \mu \mathrm{m}$ ), (a) invert microscope images of cell aggregates 7 days after seeding ADSCs on CR, (b) invert microscope images of cell alignment, 14 days after seeding ADSCs on CR , (c)h-ADSCs attachment on TR 7 days after seeding, (d) SEM image of h-ADSCs aggregates on cell replica, 7 days after seeding. Black arrows indicate cell aggregations. (e) and (h) SEM images of h-ADSCs alignment on cell replica, 14 days after seeding/ (f) and (i) SEM images of h-ADSCs aggregates on TR, 7 days after seeding, (g) a single ADSC on cell replica 7 days after seeding

Fig 6. Gene expression of hADSC, 7 and 14 days after treatment with BMP-12 and seeding on CR, TR, and DT. (a) expression of SCX as a marker of early tenocytes, (b) expression of TNMD as a marker of adult tenocytes, (c) expression of TNC as a marker of the extracellular matrix of tendons.

Fig 7. Immunocytochemistry staining to confirm tenogenic differentiation in h-ADSCs, 14 days after seeding on cell replica and tissue replica. Cell nuclei stained by DAPI (blue), SCX and TNMD protein expression stained by Alexa Fluor ${ }^{\circledR}$ 488-conjugated goat anti-rabbit antibody (green). (a1a4) SCX expression in h-ADSCs cultured on the h-tenocyte replica (scale bar $=200 \mu \mathrm{m}),(\mathrm{b} 1-\mathrm{b} 4)$ TNMD expression in h-ADSCs cultured on the h-tenocyte replica. In b4, the arrow is pointed to tenocyte replica on PDMS. (scale bar $=100 \mu \mathrm{m})$, (c1-c4) SCX expression in h-ADSCs cultured on human tendon replica, (d1-d4) TNMD expression in h-ADSCs cultured on h-tenocyte replica (scale bar $=200 \mu \mathrm{m}$ ).

Fig 8. Evaluation of Collagen I expression and tendon-like tissue formation in CR-induced tenogenic differentiation in $r$-ADSCs after implantation in ectopic condition. Cells labeled by DiI before implantation (red), Nuclei stained by DAPI (blue) and protein expression stained by Alexa Fluor ${ }^{\circledR}$ 488-conjugated (green). (a1-a4) control group including PCL electrospun mat without cells, (b1-b4) collagen I expression in r-ADSC group cultured on PCL mat, (c1-c4) collagen I expression in cell replica group cultured on PCL mat (scale bar $=200 \mu \mathrm{m})$. (d1-d3) H\&E staining in cell-containing and cell-free mats. The $\mathrm{d} 1$ demonstrate PCL electrospun mat without cells, $\mathrm{d} 2$ 


\section{References:}

demonstrate PCL electrospun mat containing cells of CR group and $\mathrm{d} 3$ demonstrate PCL electrospun mat containing r-ADSCs without any treatment 4 weeks after implantation. In $\mathrm{d} 2$, arrows are pointing to tendon-ECM like structures that formed in PCL mat containing CR cells 4 weeks after implantation (scale bar $=100 \mu \mathrm{m}$ ). (e) Percent of color density related to collagen I expression in (left) PCL electrospun mat (middle) r-ADSC group cultured on PCL electrospun mat/ (right) cell replica group cultured on PCL mat.

.1 Docheva D, Müller SA, Majewski M, Evans CH. Biologics for tendon repair. Advanced drug delivery reviews. 2015;84:222-39.

.2 Zhang C, Yuan H, Liu H, Chen X, Lu P, Zhu T, et al. Well-aligned chitosan-based ultrafine fibers committed teno-lineage differentiation of human induced pluripotent stem cells for Achilles tendon regeneration. Biomaterials. 2015;53:716-30.

.3 Gaspar D, Spanoudes K, Holladay C, Pandit A, Zeugolis D. Progress in cell-based therapies for tendon repair. Advanced Drug Delivery Reviews.56-84:240;2015.

.4 Strauss EJ, Ishak C, Jazrawi L, Sherman O, Rosen J. Operative treatment of acute Achilles tendon ruptures: an institutional review of clinical outcomes. Injury. 2007;38(7):832-8.

.5 Benjamin M, Ralphs J. Tendons and ligaments-an overview. Histology and histopathology. $1997 ; 12(4): 1135-44$.

6 Docheva D, Mueller SA, Majewski M, Evans $\mathrm{CH}$. Biologics for tendon repair. Advanced drug delivery reviews. 2015;84:222-39.

.7 Beldjilali-Labro M, Garcia Garcia A, Farhat F, Bedoui F, Grosset J-F, Dufresne M, et al.

Biomaterials in tendon and skeletal muscle tissue engineering: current trends and challenges. Materials. 2018;11(7):1116.

8 Goh JC-H, Ouyang H-W, Teoh S-H, Chan CK, Lee E-H. Tissue-engineering approach to the repair and regeneration of tendons and ligaments. Tissue engineering. 2003;9(4, Supplement 1):31-44.

.9 Costa MT, Hungria Neto JS. Comparative study of conservative and surgical methods for the treatment of acute calcaneus tendon injuries. Acta Ortopédica Brasileira. 2007;15(1):50-4.

.10 González-Quevedo D, Martínez-Medina I, Campos A, Campos F, Carriel V. Tissue engineering strategies for the treatment of tendon injuries: a systematic review and meta-analysis of animal models. Bone \& Joint Research. 2018;7(4):318-24.

.11 Karimi H, Latifi N-A, Momeni M, Sedigh-Maroufi S, Karimi A-M, Akhoondinasab M-R. Tissue expanders; review of indications, results and outcome during 15 years' experience. Burns. 2019;45(4):990-1004.

.12 Calejol, Costa-Almeida R, Reis RL, Gomes ME. A Textile Platform Using Continuous Aligned and Textured Composite Microfibers to Engineer Tendon-to-Bone Interface Gradient Scaffolds. Advanced healthcare materials. 2019:1900200. 
.13 Laranjeira M, Domingues RM, Costa-Almeida R, Reis RL, Gomes ME. 3D mimicry of native-tissuefiber architecture guides tendon-derived cells and adipose stem cells into artificial tendon constructs. Small. 2017;13(31):1700689.

.14 Sahoo S, Lok Toh S, Goh H, Cho J. PLGA nanofiber-coated silk microfibrous scaffold for connective tissue engineering. Journal of Biomedical Materials Research Part B: Applied Biomaterials. 2010;95(1):19-28.

.15 Naghashzargar E, Farè S, Catto V, Bertoldi S, Semnani D, Karbasi S, et al. Nano/micro hybrid scaffold of PCL or P3HB nanofibers combined with silk fibroin for tendon and ligament tissue engineering. Journal of applied biomaterials \& functional materials. 2015;13(2):156-68.

.16 Yousefzadeh-Chabok S, Ramezani S, Reihanian Z, Safaei M, Alijani B, Amini N. The role/of early posttraumatic neuropsychological outcomes in the appearance of latter psychiatric disorders in adults with brain trauma. Asian journal of neurosurgery. 2015;10(3):173.

.17 Learn GD, McClellan PE, Knapik DM, Cumsky JL, Webster-Wood V, Anderson JM, et al. Woven collagen biotextiles enable mechanically functional rotator cuff tendon regeneration during repair of segmental tendon defects in vivo. Journal of Biomedical Materials Research Part B: Applied Biomaterials. 2019;107(6):1864-76.

.18 Shen H, Gelberman RH, Silva MJ, Sakiyama-Elbert SE, Thomopoulos S. BMP12 induces tenogenic differentiation of adipose-derived stromal cells. PloS one. 2013;8(10):e77613.

.19 Barboni B, Curini V, Russo V, Mauro A, Di Giacinto O, Marchisio M, et al. Indirect co-culture with tendons or tenocytes can program amniotic epithelial cells towards stepwise tenogenic differentiation. PloS one. 2012;7(2):e30974.

.20 Kraus A, Luetzenberg R, Abuagela N, Hollenberg S, Infanger M. Spheroid formation and modulation of tenocyte-specific gene expression under simulated microgravity. Muscles, ligaments and tendons journal. 2017;7(3):411.

.21 Dale TP, Mazher S, Webb WR, Zhou J, Maffulli N, Chen G-Q, et al. Tenogenic differentiation of human embryonic stem cells. Tissue Engineering Part A. 2018;24(5-6):361-8.

.22 Wu S, Wang Y, Streubel PN, Duan B. Living nanofiber yarn-based woven biotextiles for tendon tissue engineering using cell tri-culture and mechanical stimulation. Acta biomaterialia. 2017;62:102-15. .23 Ramezani S, Hadjighassem M, Vousooghi N, Párvaresh M, Arbabi F, Amini N, et al. The role of protein kinase $B$ signaling pathway in anti-cancer effect of rolipram on glioblastoma multiforme: an in vitro study. Basic and clinical neuroscience. 2017;8(4):325.

.24 Alizadeh R, Ramezanpour F, Mohammadi A, Eftekharzadeh M, Simorgh S , Kazemiha M, et al. Differentiation of human olfactory system-derived stem cells into dopaminergic neuron-like cells: A comparison between olfactory bulb and mucosa as two sources of stem cells. Journal of Cellular Biochemistry.

.25 Wang Q-W, Chen Z-L, Piao Y-J. Mesenchymal stem cells differentiate into tenocytes by bone morphogenetic protein (BMP) 12 gene transfer. Journal of bioscience and bioengineering. 2005;100(4):418-22.

.26 Maghdouri-White $\mathrm{Y}$, Petrova S, Sori N, Polk S, Wriggers $\mathrm{H}$, Ogle R, et al. Electrospun silk-collagen scaffolds and BMP-13 for ligament and tendon repair and regeneration. Biomedical Physics \& Engineering Express. 2018;4(2):025013.

.27 Hogan M, Girish K, James R, Balian G, Hurwitz S, Chhabra A. Growth differentiation factor-5 regulation of extracellular matrix gene expression in murine tendon fibroblasts. Journal of tissue engineering and regenerative medicine. 2011;5(3):191-200.

.28 Kargozar S, Mozafari M, Hill RG, Milan PB, Joghataei MT, Hamzehlou S, et al. Synergistic combination of bioactive glasses and polymers for enhanced bone tissue regeneration. Materials Today: Proceedings. 2018;5(7):15532-9. 
.29 Molloy T, Wang Y, Murrell GA. The roles of growth factors in tendon and ligament healing. Sports medicine. 2003;33(5):381-94.

.30 Bonakdar S, Mahmoudi M, Montazeri L, Taghipoor M, Bertsch A, Shokrgozar MA, et al. Cellimprinted substrates modulate differentiation, redifferentiation, and transdifferentiation. ACS applied materials \& interfaces. 2016;8(22):13777-84.

.31 Yan Z, Yin H, Nerlich M, Pfeifer CG, Docheva D. Boosting tendon repair: interplay of cells, growth factors and scaffold-free and gel-based carriers. Journal of experimental orthopaedics. 2018;5(1):1. .32 Fisher OZ, Khademhosseini A, Langer R, Peppas NA. Bioinspired materials for controlling stem cell fate. Accounts of chemical research. 2009;43(3):419-28.

.33 Pieuchot L, Marteau J, Guignandon A, Dos Santos T, Brigaud I, Chauvy P-F, et al. Curvotaxis directs cell migration through cell-scale curvature landscapes. Nature communications. 2018;9(1):3995. .34 Rinoldi C, Fallahi A, Yazdi I, Campos Paras J, Kijeńska-Gawrońska E, Trujillo-de Santiago G, et al. Mechanical and biochemical stimulation of 3D multi-layered scaffolds for tendon tissue engineering. ACS Biomaterials Science \& Engineering. 2019.

.35 Islam A, Mbimba T, Younesi M, Akkus O. Effects of substrate stiffness on the tenoinduction of human mesenchymal stem cells. Acta biomaterialia. 2017;58:244-53.

.36 Kilian KA, Bugarija B, Lahn BT, Mrksich M. Geometric cues for directing the differentiation of mesenchymal stem cells. Proceedings of the National Academy of Sciences. 2010;107(11):4872-7.

.37 McBeath R, Pirone DM, Nelson CM, Bhadriraju K, Chen CS. Cell shape, cytoskeletal tension, and RhoA regulate stem cell lineage commitment. Developmental/cell. 2004;6(4):483-95.

.38 Harris GM, Piroli ME, Jabbarzadeh E. Deconstructing the effects of matrix elasticity and geometry in mesenchymal stem cell lineage commitment. Advanced functional materials. 2014;24(16):2396-40.3

.39 Bao M, Xie J, Piruska A, Huck WT. 3D microniches reveal the importance of cell size and shape. Nature communications. 2017;8(1):1962.

.40 Engler AJ, Sen S, Sweeney HL, Discher DE. Matrix elasticity directs stem cell lineage specification. Cell. 200.89-677:(4)126;6

.41 Yang G, Lin H, Rothrauff BB, Yu S, Tuan RS. Multilayered polycaprolactone/gelatin fiber-hydrogel composite for tendon tissue engineering. Acta biomaterialia. 2016;35:68-76.

.42 Tong WY, Shen W, Yeung CW, Zhao Y, Cheng SH, Chu PK, et al. Functional replication of the tendon tissue microenvironment by a bioimprinted substrate and the support of tenocytic differentiation of mesenchymal stem cells. Biomaterials. 2012;33(31):7686-98.

.43 Miyoshi H, Adachi T. Topography design concept of a tissue engineering scaffold for controlling cell function and fate through actin cytoskeletal modulation. Tissue Engineering Part B: Reviews. 2014;20(6):609-27.

.44 Newman P, Niño JLG, Graney P, Razal JM, Minett Al, Ribas J, et al. Relationship between nanotopographical alignment and stem cell fate with live imaging and shape analysis. Scientific reports. 2016;6:37909.

.45 Huang J, Chen Y, Tang C, Fei Y, Wu H, Ruan D, et al. The relationship between substrate topography and stem cell differentiation in the musculoskeletal system. Cellular and molecular life sciences. 2019;76(3):505-21.

.46 Yang K, Jung K, Ko E, Kim J, Park KI, Kim J, et al. Nanotopographical manipulation of focal adhesion formation for enhanced differentiation of human neural stem cells .ACS applied materials \& interfaces. 2013;5(21):10529-40.

.47 Kong YP, Tu CH, Donovan PJ, Yee AF. Expression of Oct4 in human embryonic stem cells is dependent on nanotopographical configuration. Acta biomaterialia. 2013;9(5):6369-80. 
.48 Yang HS, Lee B, Tsui JH, Macadangdang J, Jang SY, Im SG, et al. Electroconductive nanopatterned substrates for enhanced myogenic differentiation and maturation. Advanced healthcare materials. 2016;5(1):137-45.

.49 Yin Z, Chen X, Song H-x, Hu J-j, Tang Q-m, Zhu T, et al. Electrospun scaffolds for multiple tissues regeneration in vivo through topography dependent induction of lineage specific differentiation. Biomaterials. 2015;44:173-85.

.50 Zhou K, Feng B, Wang W, Jiang Y, Zhang W, Zhou G, et al. Nanoscaled and microscaled parallel topography promotes tenogenic differentiation of ASC and neotendon formation in vitro. International) journal of nanomedicine. 2018;13:3867.

.51 Kishore V, Bullock W, Sun X, Van Dyke WS, Akkus O. Tenogenic differentiation of humán MSCs induced by the topography of electrochemically aligned collagen threads. Biomaterials. 2012;33(7):2137-44.

.52 Salmasi S, Kalaskar DM, Yoon W-W, Blunn GW, Seifalian AM. Role of nanotopography in the development of tissue engineered 3D organs and tissues using mesenchymal stem cells. World journal of stem cells. 2015;7(2):266.

.53 Mahmoudi M, Bonakdar S, Shokrgozar MA, Aghaverdi H, Hartmann R, Pick A, et al. Cellimprinted substrates direct the fate of stem cells. ACS nano. 2013;7(10):8379-84.

.54 Mashinchian O, Bonakdar S, Taghinejad H, Satarifard V, Heidari M, Majidi M, et al. CellImprinted Substrates Act as an Artificial Niche for Skin Regeneration. ACS applied materials \& interfaces. 2014;6(15):13280-92.

.55 Kamguyan K, Katbab AA, Mahmoudi M, Thormann E, Moghaddam SZ, Moradi L, et al. An engineered cell-imprinted substrate directs osteogenic differentiation in stem cells. Biomaterials science. 2018;6(1):189-99.

.56 English A, Azeem A, Spanoudes K, Jones E, Tripathi B, Basu N, et al. Substrate topography: a valuable in vitro tool, but a clinical red herring for in vivo tenogenesis. Acta biomaterialia. 2015;27:3-12. .57 Amini N, Vousooghi N, Hadjighassem M, Bakhtiyari M, Mousavi N, Safakheil H, et al. Efficacy of human adipose tissue-derived stem cells on neonatal bilirubin encephalopathy in rats. Neurotoxicity research. 2016;29(4):514-24.

.58 Kapur R, Rudolph AS. Cellular and cytoskeleton morphology and strength of adhesion of cells on self-assembled monolayers of organosilanes. Experimental cell research. 1998.85-275:(1)244;

.59 Shao Y, Mann JM, Chen W, Fu J. Global architecture of the F-actin cytoskeleton regulates cell shape-dependent endothelial mechanotransduction. Integrative Biology. 2014;6(3):300-11.

.60 Heydari T, Heidari M, Mashinchian O, Wojcik M, Xu K, Dalby MJ, et al. Development of a virtual cell model to predict cell response to substrate topography. ACS nano. 2017;11(9):9084-92.

.61 Teo BKK, Wong ST, Lim CK, Kung TY, Yap CH, Ramagopal Y, et al. Nanotopography modulates mechanotransduction of stem cells and induces differentiation through focal adhesion kinase. ACS nano. 2013;7(6):4785-98.

.62 Rubin J, Styner M, Uzer G. Physical Signals May Affect Mesenchymal Stem Cell Differentiation via Epigenetic Controls. Exercise and sport sciences reviews.7-42:(1)46;2018 .

.63 Yang $\mathrm{Y}$, Wang K, Gu X, Leong KW. Biophysical regulation of cell behavior-cross talk between substrate stiffness and nanotopography. Engineering. 2017;3(1):36-54.

.64 Pridgen BC, Woon CY, Kim M, Thorfinn J, Lindsey D, Pham H, et al. Flexor tendon tissue engineering: acellularization of human flexor tendons with preservation of biomechanical properties and biocompatibility. Tissue Engineering Part C: Methods. 2011;17(8):819-28.

.65 Raghavan SS, Woon CY, Kraus A, Megerle K, Choi MS, Pridgen BC, et al. Human flexor tendon tissue engineering: decellularization of human flexor tendons reduces immunogenicity in vivo. Tissue Engineering Part A. 2011;18(7-8):796-805. 
.66 Subramony SD, Dargis BR, Castillo M, Azeloglu EU, Tracey MS, Su A, et al .The guidance of stem cell differentiation by substrate alignment and mechanical stimulation. Biomaterials. 2013;34(8):194253.

.67 Yin Z, Nguyen TH, Chen X, Ouyang H-W, editors. Cell Orientation Affects Human Tendon Stem Cells Differentiation. 13th International Conference on Biomedical Engineering; 2009: Springer. .68 Wu S, Peng H, Li X, Streubel PN, Liu Y, Duan B. Effect of scaffold morphology and cell co-culture on tenogenic differentiation of HADMSC on centrifugal melt electrospun poly (L-lactic acid) fibrous meshes. Biofabrication. 2017;9(4):044106.

.69 Rajpar I, Barrett JG. Optimizing growth factor induction of tenogenesis in three-dimensional culture of mesenchymal stem cells. Journal of tissue engineering. 2019;10:2041731419848776.

.70 Lee JY, Zhou Z, Taub PJ, Ramcharan M, Li Y, Akinbiyi T, et al. BMP-12 treatment of adult mesenchymal stem cells in vitro augments tendon-like tissue formation and defect repair in vivo. PloS one. 2011;6(3):e17531.

.71 Zarychta-Wiśniewska W, Burdzinska A, Kulesza A ,Gala K, Kaleta B, Zielniok K, et al. Bmp-12 activates tenogenic pathway in human adipose stem cells and affects their immunomodulatory and secretory properties. BMC cell biology. 2017;18(1):13.

.72 Dai L, Hu X, Zhang X, Zhu J, Zhang J, Fu X, et al. Different tenogenic differentiation capacities of different mesenchymal stem cells in the presence of BMP-12. Journal of translational medicine. 2015;13(1):200.

.73 Bottagisio M, Lopa S, Granata V, Talò G, Bazzocchi C, Moretti M, et al. Different combinations of growth factors for the tenogenic differentiation of bone marrow mesenchymal stem cells in monolayer culture and in fibrin-based three-dimensional constructs. Differentiation. 2017;95:44-53.

.74 Majewski M, Heisterbach $\mathrm{P}$, Jaquiéry $\mathrm{C}$, Dürselen $\mathrm{L}$, Todorov A, Martin I, et al. Improved tendon healing using bFGF, BMP-12 and TGFB1 in a rat model. Eur Cell Mater. 2018;35:318-34.

.75 Chamberlain CS, Lee J-S, Leiferman EM, Maassen NX, Baer GS, Vanderby R, et al. Effects of BMP12-releasing sutures on Achilles tendon healing. Tissue Engineering Part A. 2014;21(5-6):916-27.

.76 Ning L-J, Zhang Y-J, Zhang Y, Qing Q, Jiang Y-L, Yang J-L, et al. The utilization of decellularized tendon slices to provide an inductive microenvironment for the proliferation and tenogenic differentiation of stem cells. Biomaterials. 2015;52:539-50.

.77 Burk J, Plenge A, Brehm W, Heller S, Pfeiffer B, Kasper C. Induction of tenogenic differentiation mediated by extracellular tendon matrix and short-term cyclic stretching. Stem cells international. 2016;2016.

.78 Liu H, Zhu S, Zhang C, Lu P, Hu J, Yin Z, et al. Crucial transcription factors in tendon development and differentiation: their potential for tendon regeneration. Cell and tissue research. 2014;356(2):28798.

.79 Dex S, Lin D, Shukunami C, Docheva D. Tenogenic modulating insider factor: Systematic assessment on the functions of tenomodulin gene. Gene. 2016;587(1):1-17.

.80 Havis E, Bonnin M-A, de Lima JE, Charvet B, Milet C, Duprez D. TGF $\beta$ and FGF promote tendon progenitor fate and act downstream of muscle contraction to regulate tendon differentiation during chick limb development. Development. 2016;143(20):3839-51.

.81 Orr SB, Chainani A, Hippensteel KJ, Kishan A, Gilchrist C, Garrigues NW, et al. Aligned multilayered electrospun scaffolds for rotator cuff tendon tissue engineering. Acta biomaterialia. 2015;24:117-26.

.82 Hart M, Lauer J, Selig M, Hanak M, Walters B, Rolauffs B. Shaping the Cell and the Future: Recent Advancements in Biophysical Aspects Relevant to Regenerative Medicine. Journal of Functional Morphology and Kinesiology. 2018;3(1):2.

.83 Maharam E, Yaport M, Villanueva NL, Akinyibi T, Laudier D, He Z, et al. Rho/Rock signal transduction pathway is required for MSC tenogenic differentiation. Bone research. 2015;3:1.5015 
.84 Liu Y, Suen C-W, Zhang J-f, Li G. Current concepts on tenogenic differentiation and clinical applications. Journal of orthopaedic translation. 2017;9:28-42.

.85 Otabe K, Nakahara H, Hasegawa A, Matsukawa T, Ayabe F, Onizuka N, et al. Transcription factor Mohawk controls tenogenic differentiation of bone marrow mesenchymal stem cells in vitro and in vivo. Journal of Orthopaedic Research. 2015;33(1):1-8.

.86 Docheva D, Hunziker EB, Fässler R, Brandau O. Tenomodulin is necessary for tenocyte proliferation and tendon maturation. Molecular and cellular biology. 2005;25(2):699-705,

.87 Shukunami C, Takimoto A, Oro M, Hiraki Y. Scleraxis positively regulates the expression of tenomodulin, a differentiation marker of tenocytes. Developmental biology. 20.47-234:(1)298;06 .88 Xu Y, Dong S, Zhou Q, Mo X, Song L, Hou T, et al. The effect of mechanical stimulation on the maturation of TDSCs-poly (L-lactide-co-e-caprolactone)/collagen scaffold constructs for tendon tissue engineering. Biomaterials. 2014;35.72-2760:(9)

$.89 \mathrm{Ni}$ M, Rui YF, Tan Q, Liu Y, Xu LL, Chan KM, et al. Engineered scaffold-free tendon tissue produced by tendon-derived stem cells. Biomaterials. 2013;34(8):2024-37.

.90 Dalby MJ, Gadegaard N, Oreffo RO. Harnessing nanotopography and integrin-matrix interactions to influence stem cell fate. Nature materials. 2014;13(6):558. 
Table 1. Sequences of Primers Used in Real-Time PCR

\begin{tabular}{|l|l|}
\hline Primer & Sequence (5'-3') \\
\hline TNMD-F & TGTGGACTGGTGTTTGGTATCC \\
\hline TNMD-R & CCATTGCTGTAGAAAGTGTGCTC \\
\hline SCX-F & ACACCCAGCCCAAACAGATC \\
\hline SCX-R & GCCACCTCCTAACTGCGAATC \\
\hline TNC-F & CAGCCAAAGAGACCTTCACAAC \\
\hline TNC-R & CTTGCCATTCCTCCATTCCAG \\
\hline Gapdh-F & TCAAGATCATCAGCAATGCCTC \\
\hline Gapdh-R & GTCATGAGTCCTTCCACGATAC \\
\hline
\end{tabular}

$\mathrm{F}$ : forward and $\mathrm{R}$ : reverse 

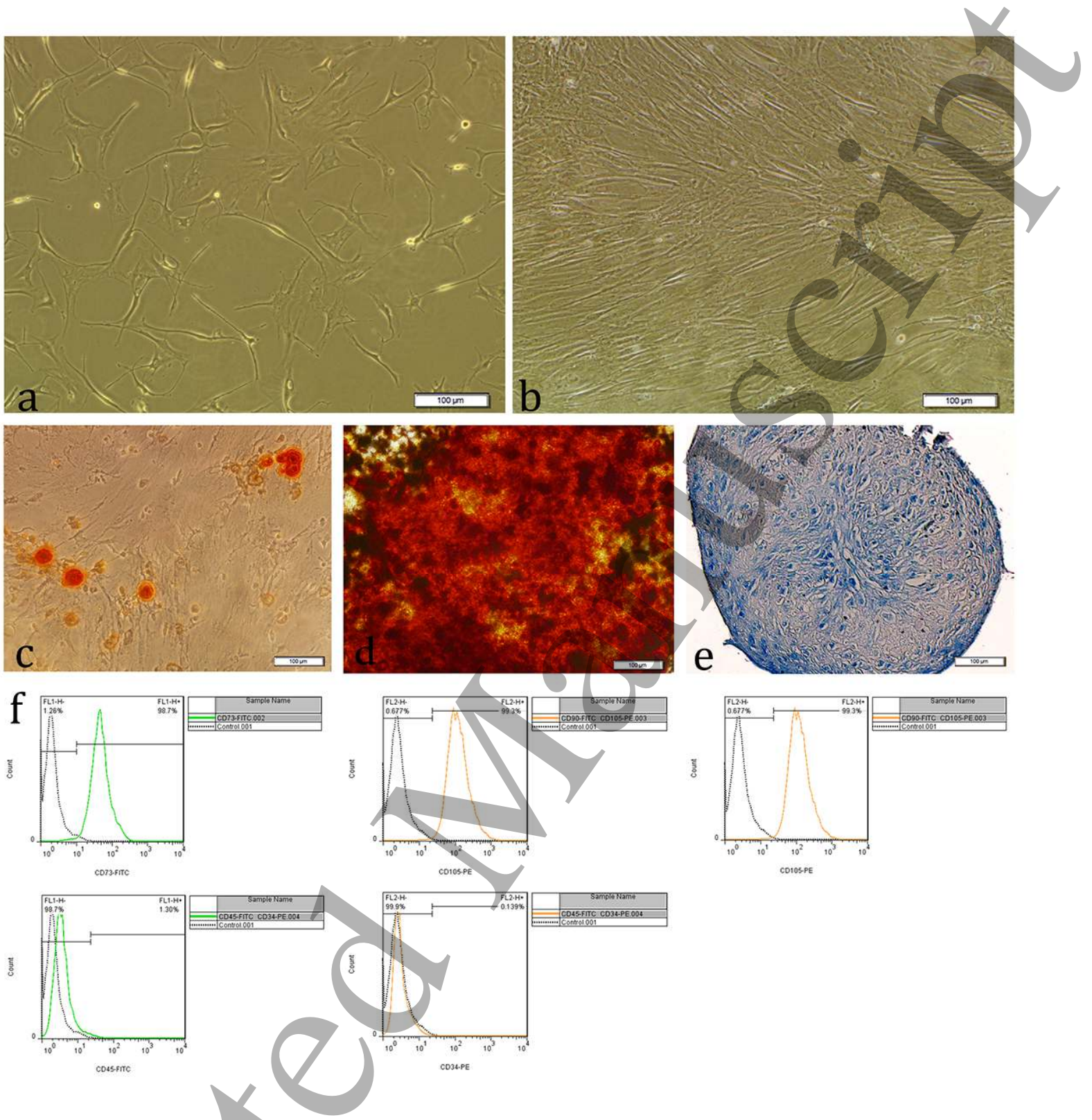


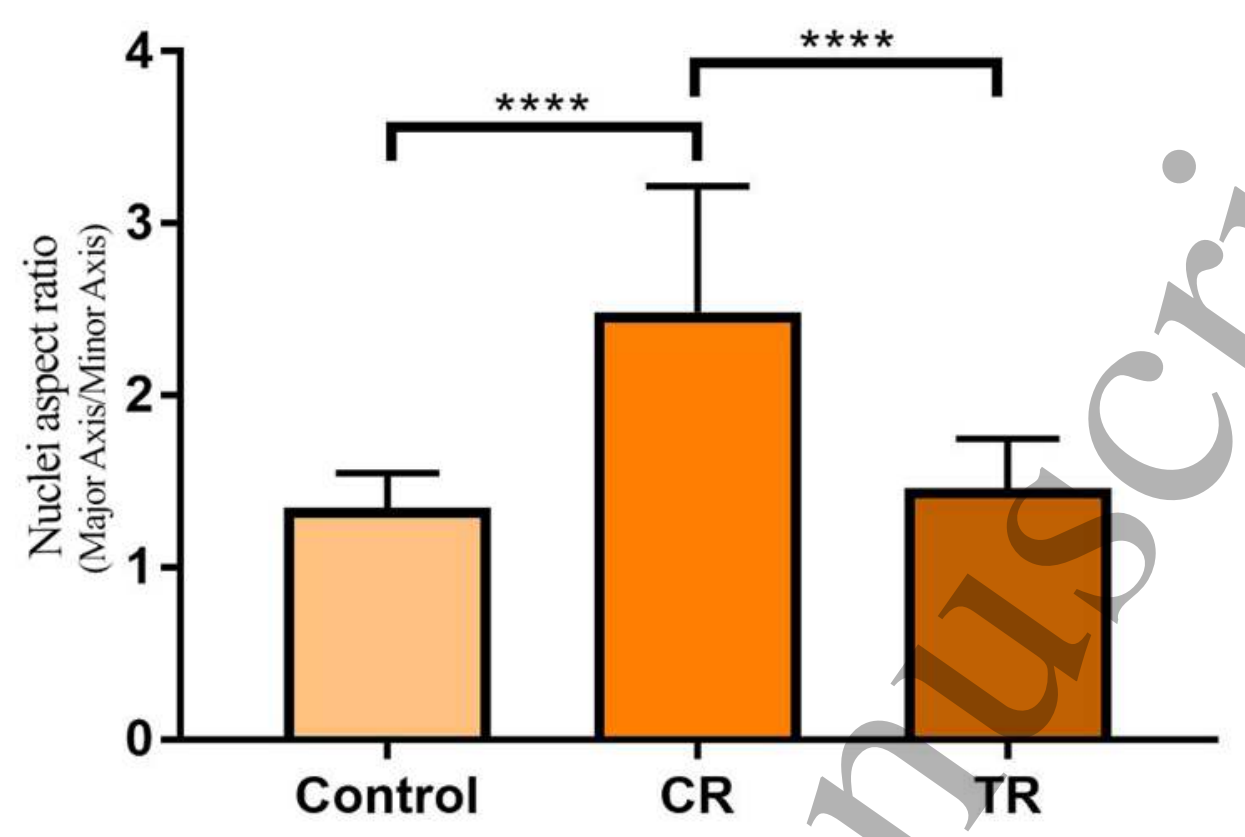




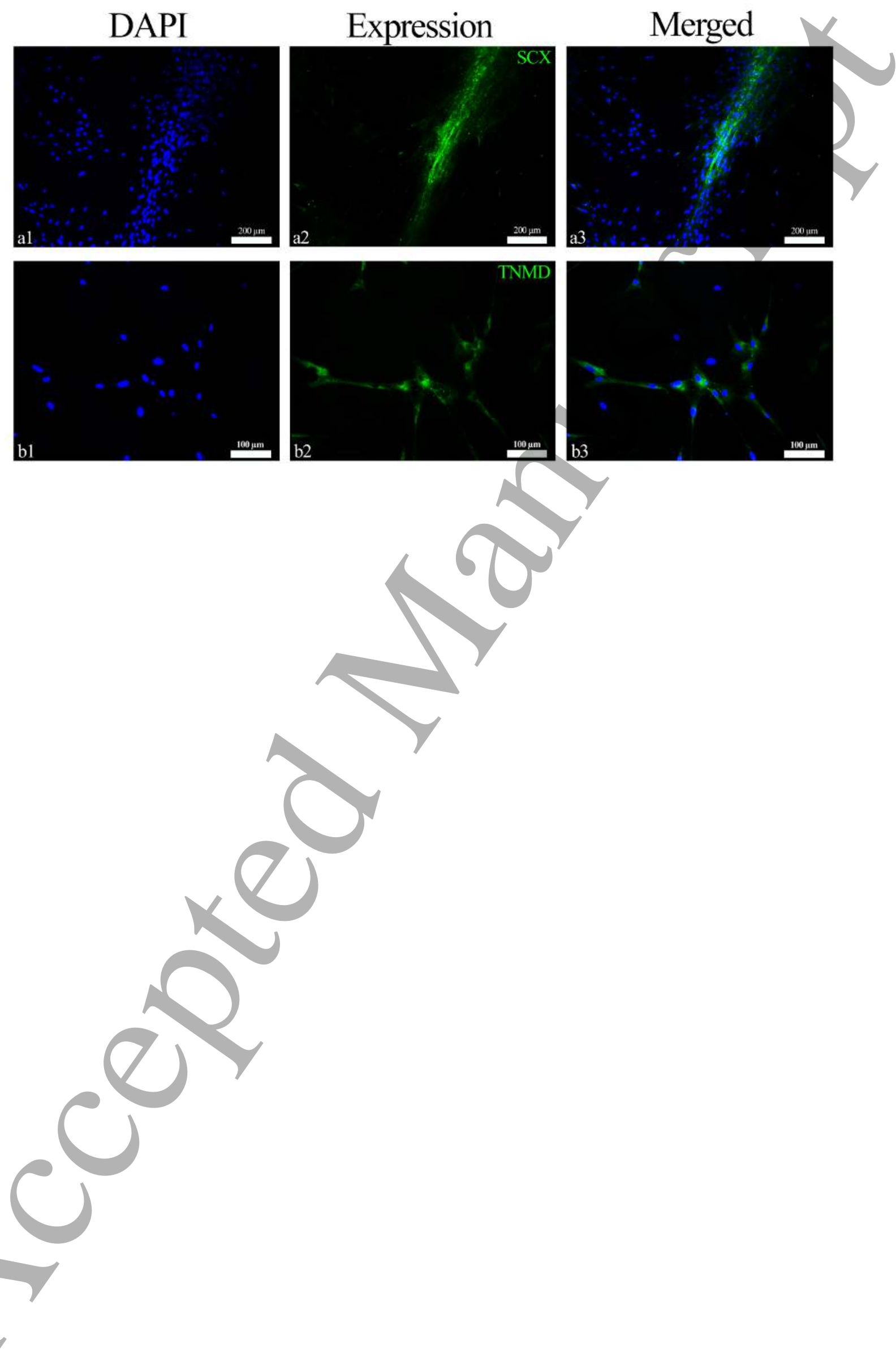



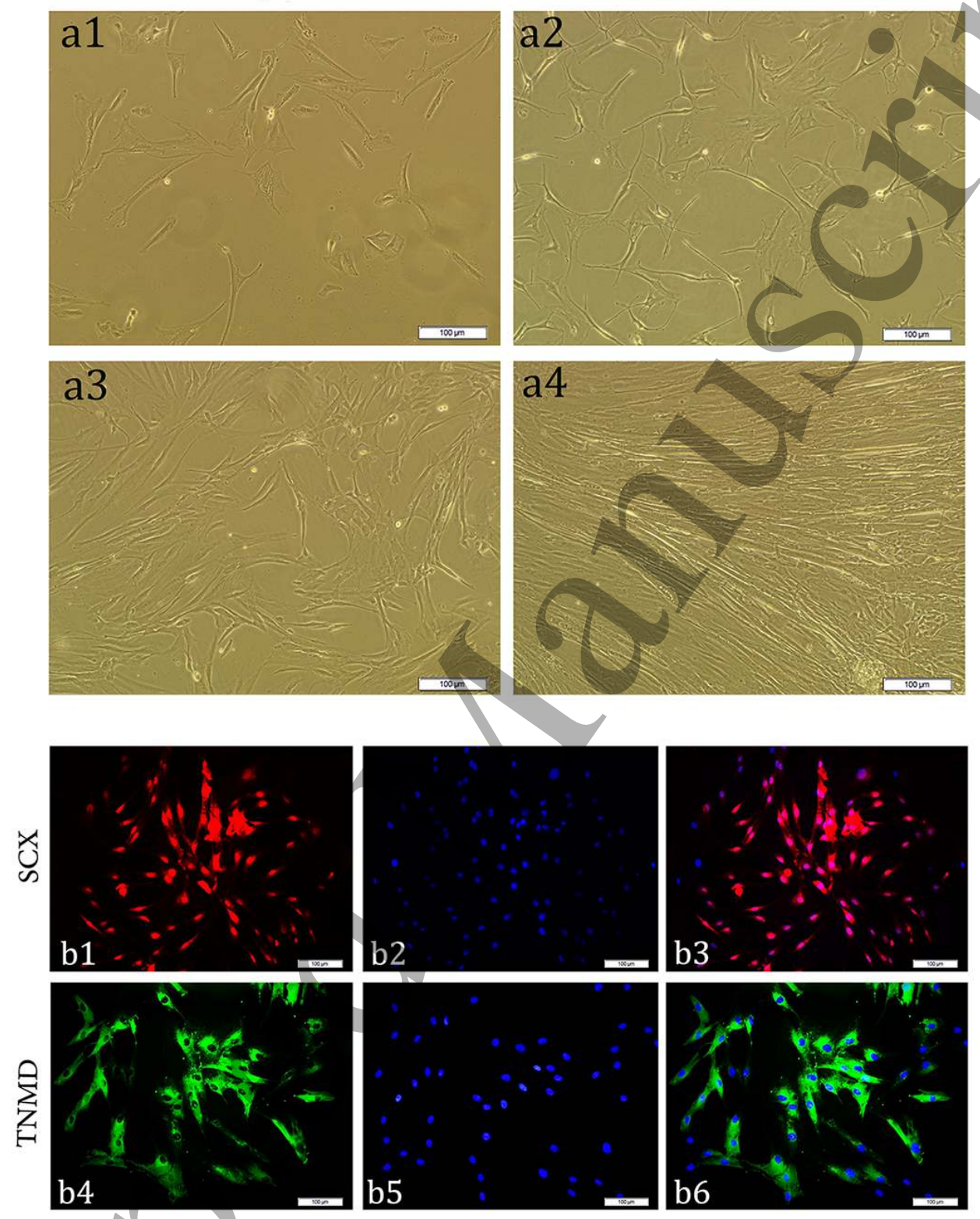

4

53 

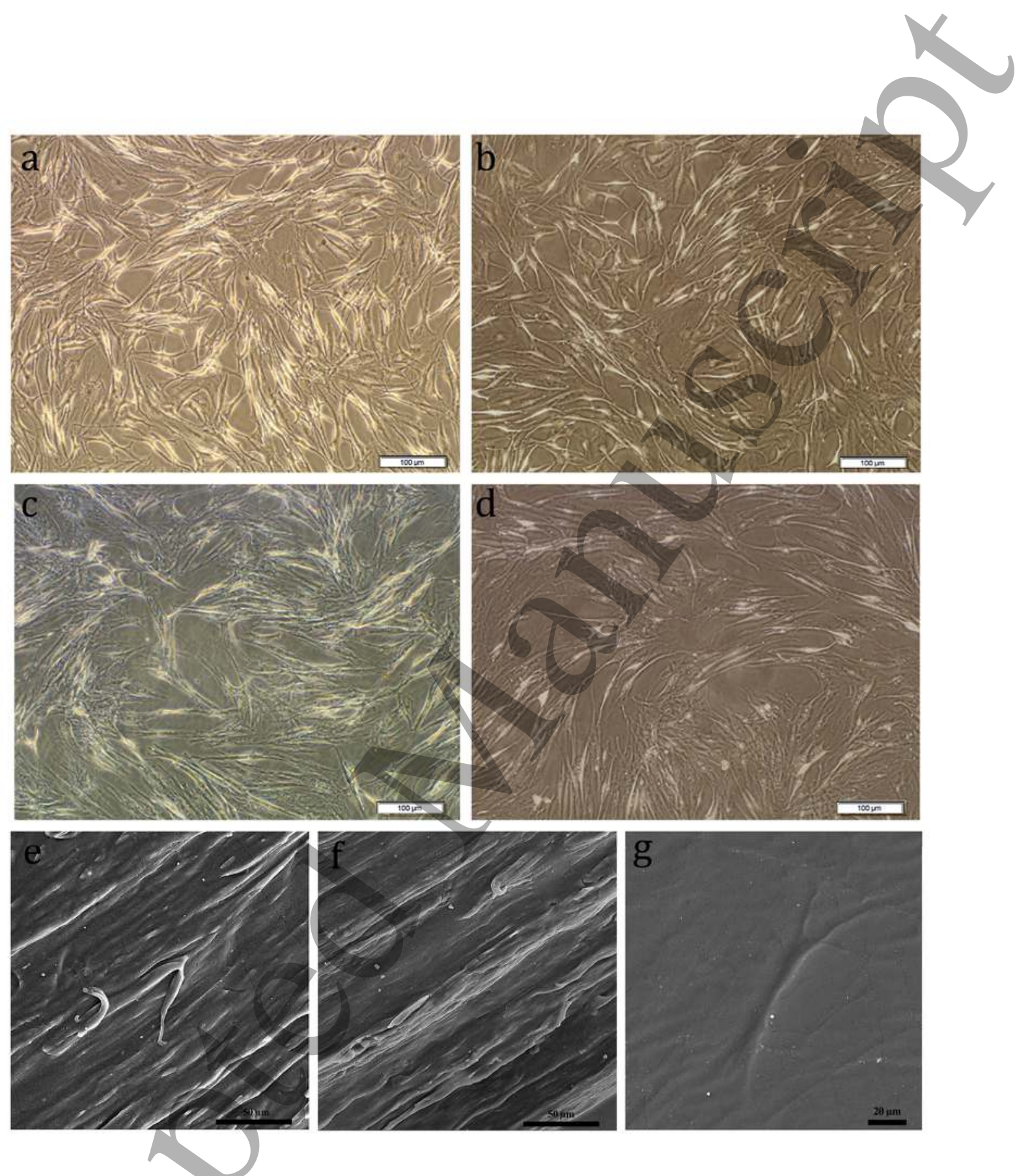

5

53

54

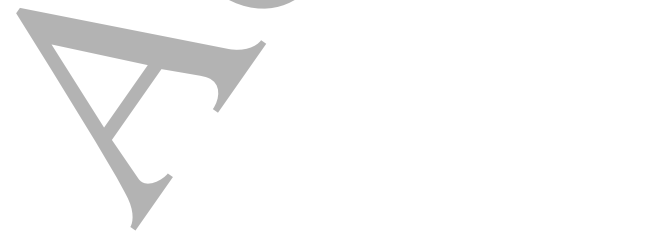



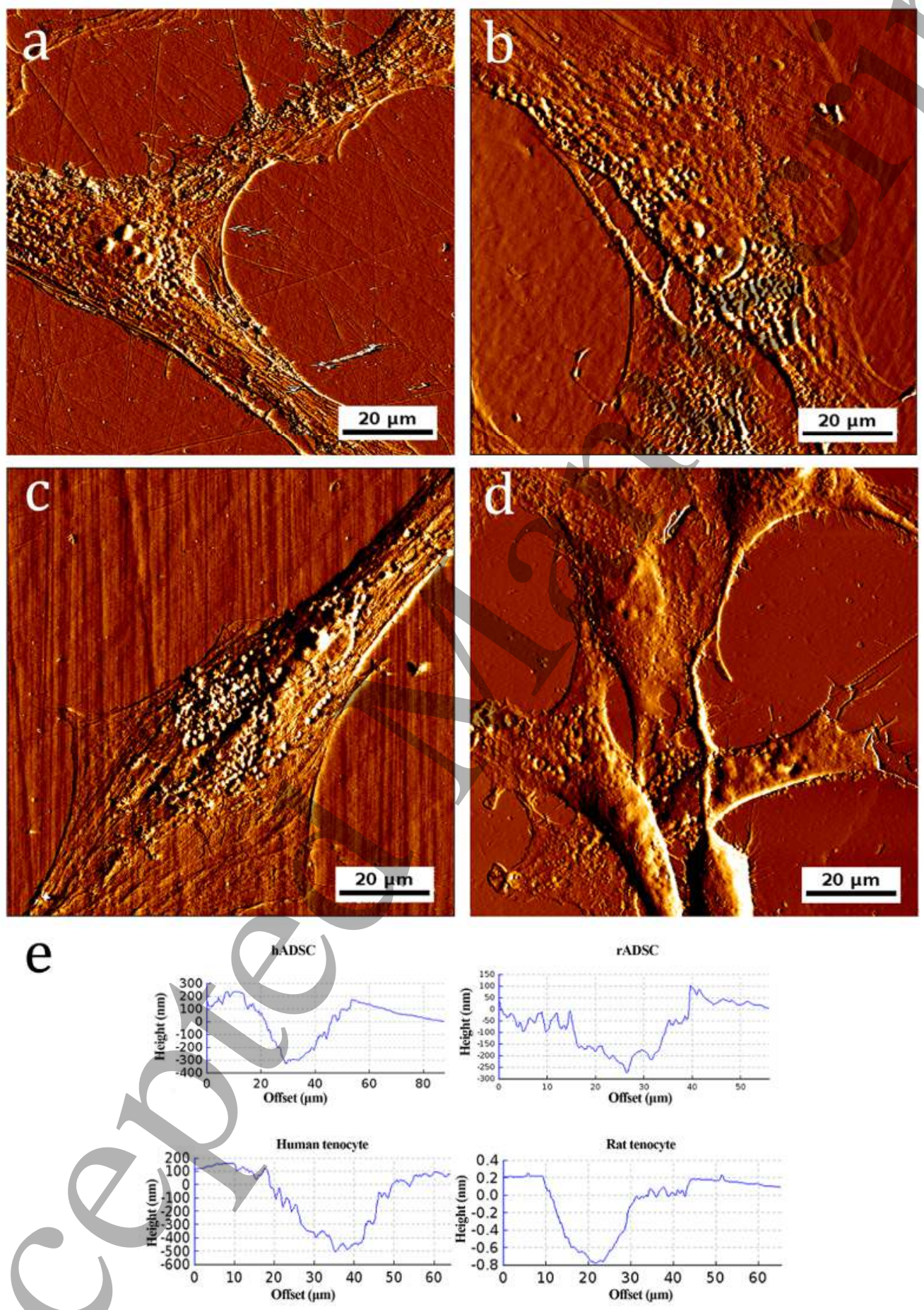


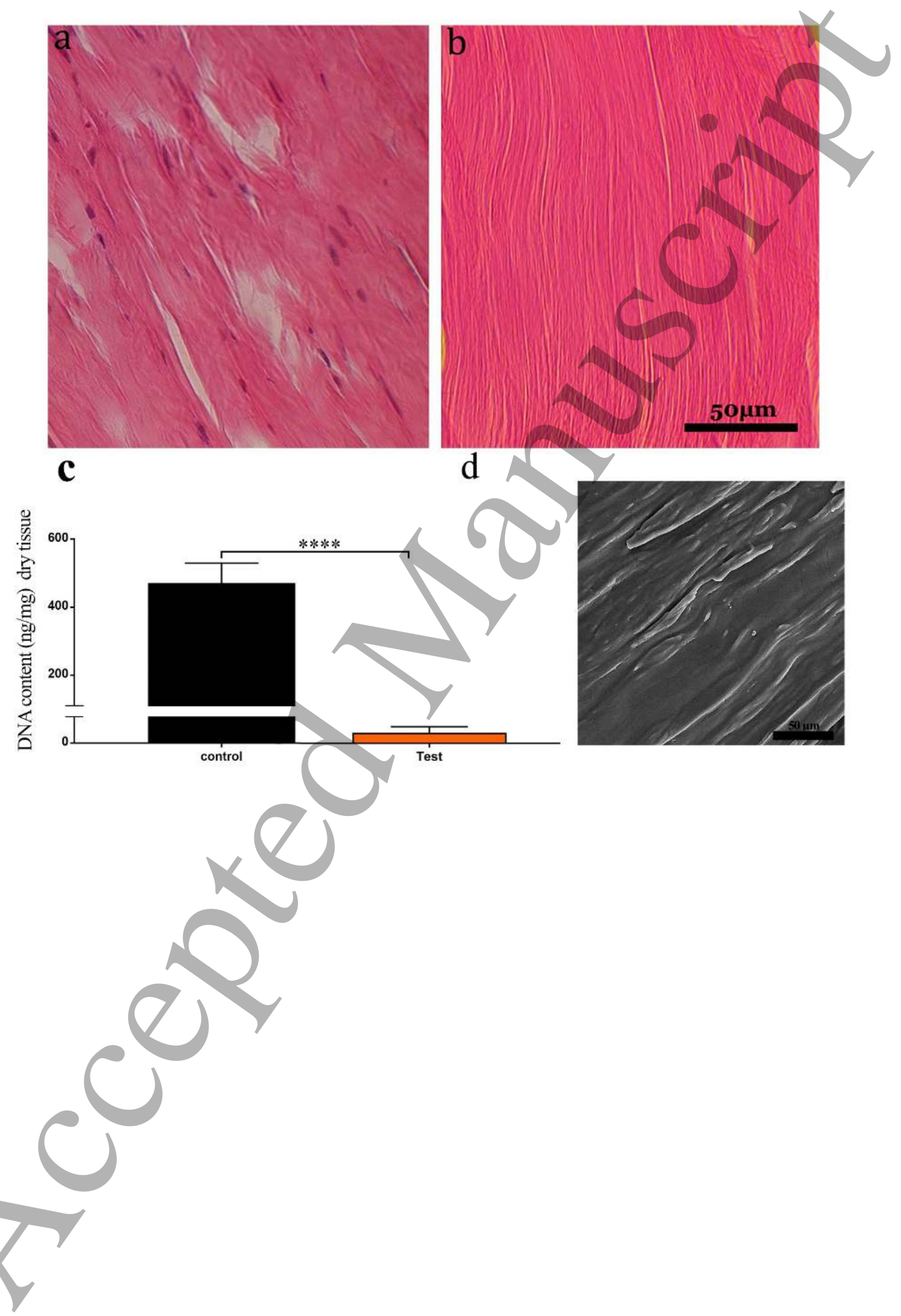



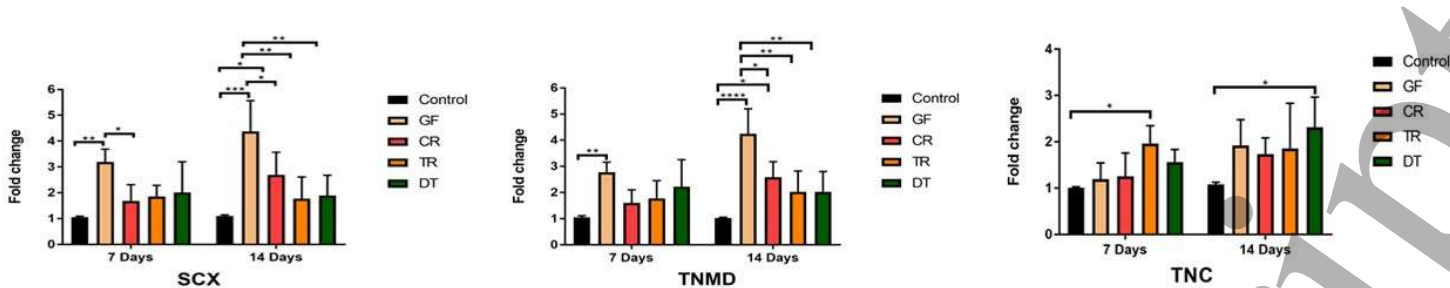

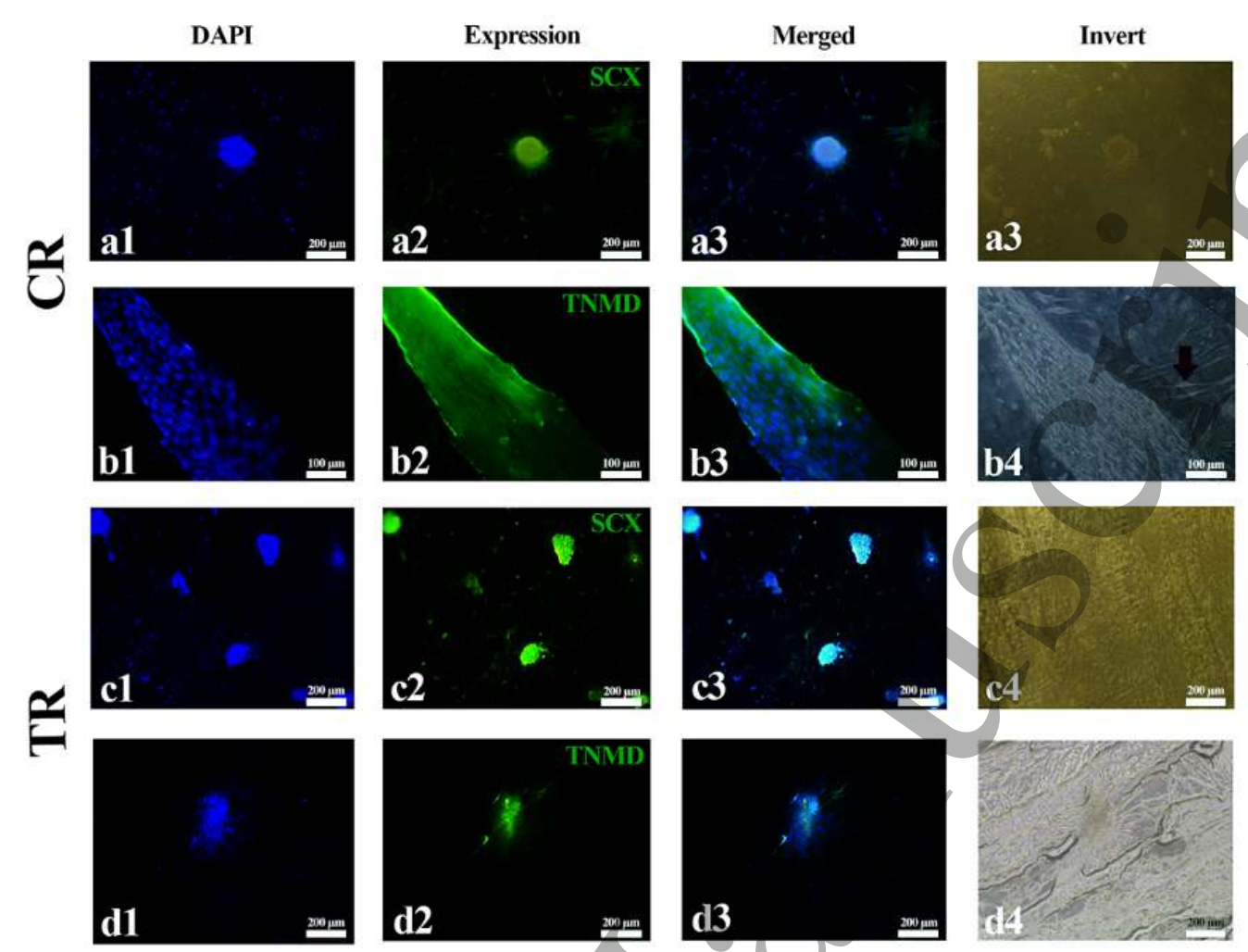


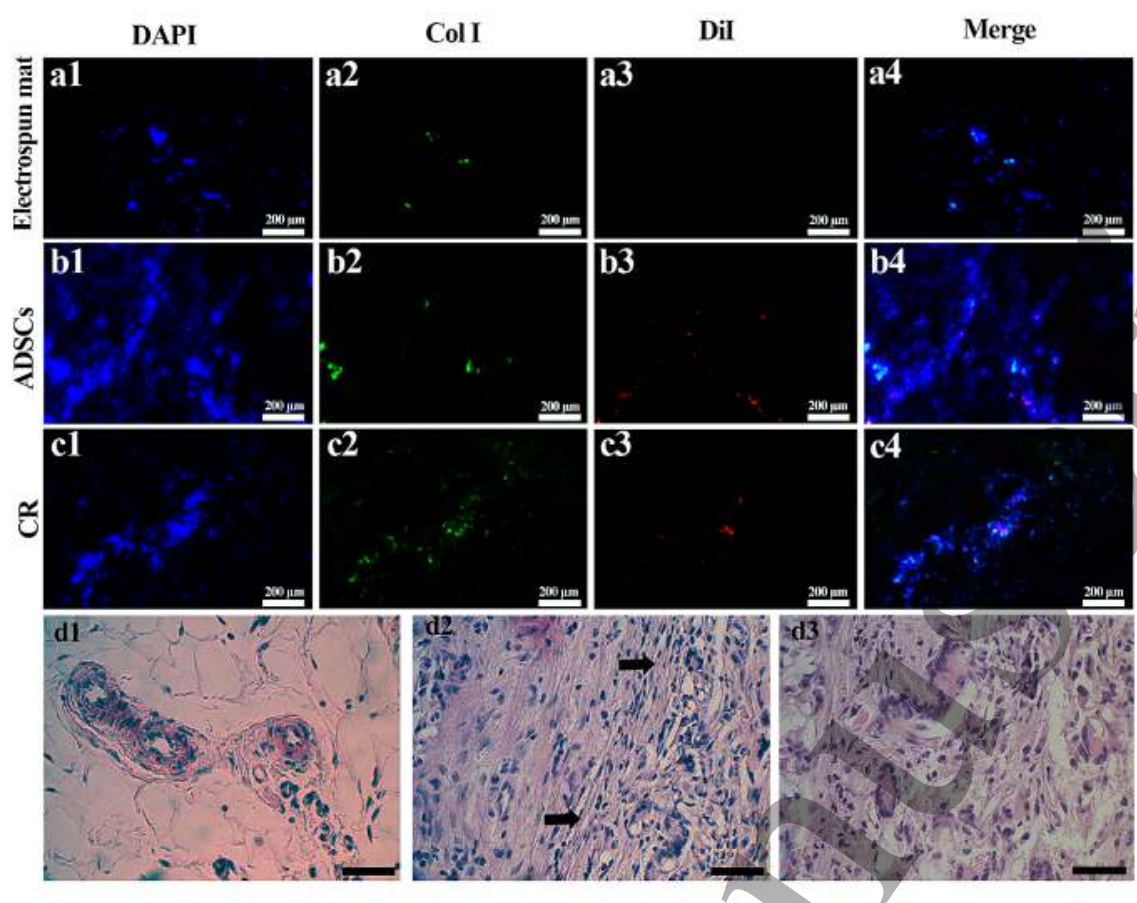

e

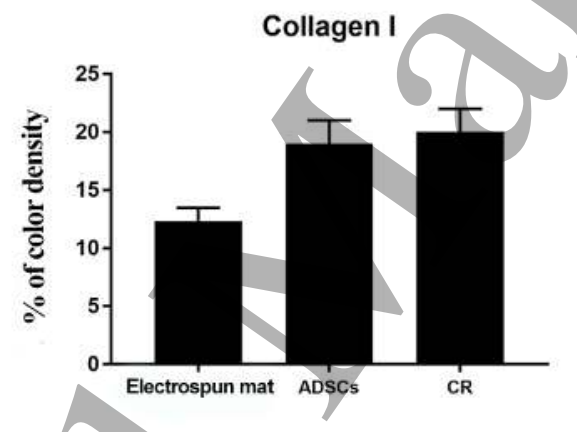


Graphical abstract

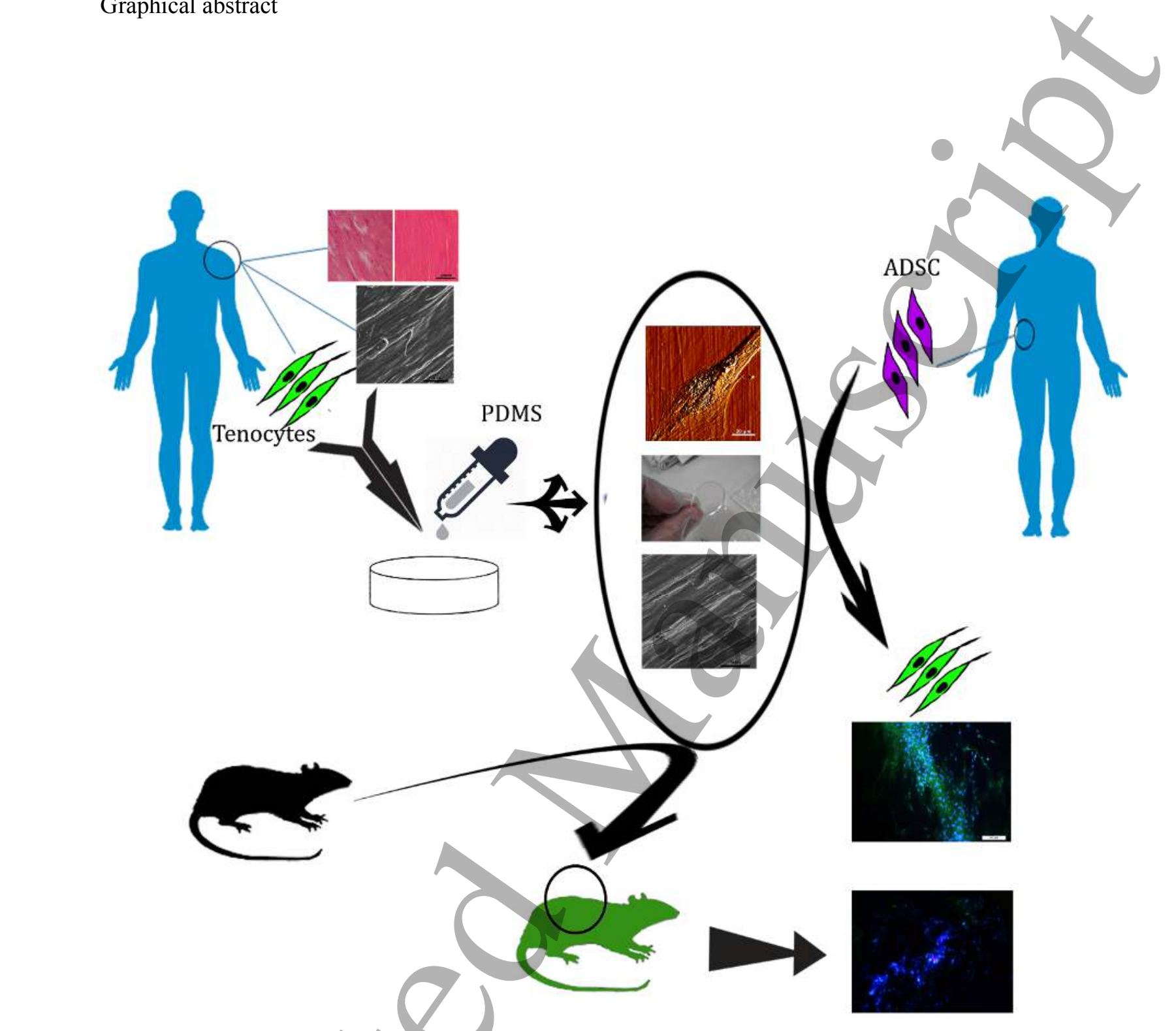

44

46

47

48

49

51

52

53

54

56

57 